\title{
Cx30 exhibits unique characteristics including a long half-life when assembled into gap junctions
}

\author{
John J. Kelly ${ }^{1}$, Qing Shao', Daniel J. Jagger² and Dale W. Laird ${ }^{1,3, *}$
}

\begin{abstract}
In the present study we investigated the life cycle, trafficking, assembly and cell surface dynamics of a poorly characterized connexin family member, connexin 30 (Cx30; also known as GJB6), which plays a critical role in skin health and hearing. Unexpectedly, Cx30 localization at the cell surface and gap junctional intercellular communication was not affected by prolonged treatments with the endoplasmic reticulum (ER)-Golgi transport inhibitor brefeldin $\mathrm{A}$ or the protein synthesis inhibitor cycloheximide, whereas Cx43 (also known as GJA1) was rapidly cleared. Fluorescent recovery after photobleaching revealed that Cx30 plaques were rebuilt from the outer edges in keeping with older channels residing in the inner core of the plaque. Expression of a dominant-negative form of Sar1 GTPase led to the accumulation of Cx30 within the ER, in contrast to a report that Cx30 traffics via a Golgi-independent pathway. Co-expression of Cx30 with Cx43 revealed that these connexins segregate into distinct domains within common gap junction plaques, suggesting that their assembly is governed by different mechanisms. In summary, Cx30 was found to be an unusually stable, long-lived connexin (half-life $>12 \mathrm{~h}$ ), which may underlie its specific role in the epidermis and cochlea.
\end{abstract}

KEY WORDS: Connexin, Gap junction, Cx30, Connexin 30, Life cycle, Trafficking

\section{INTRODUCTION}

Gap junctions are intercellular channels that permit the direct transfer of ions and small molecules $(<1-1.5 \mathrm{kDa}$ in size) between adjacent cells, in a process termed gap junctional intercellular communication (GJIC) (Alexander and Goldberg, 2003). Each gap junction channel, composed of two interdocked hexameric connexons provided by apposing cells, can be composed of single (homotypic) or mixed (heterotypic) connexin family members. Under specific physiological conditions undocked connexons at the cell surface can also function as hemichannels that exchange small molecules between the intra- and extracellular environments (Evans et al., 2006). Given that 21 connexin subtypes exist in humans and that most cell types express more than one connexin at any one time, a huge variety of gap junction and hemichannel configurations are possible (Laird, 2006). This complexity is evident in the skin epidermis, where up to ten different connexins are expressed at various stages of the keratinocyte life cycle (Martin et al., 2014).

\footnotetext{
${ }^{1}$ Department of Anatomy and Cell Biology, University of Western Ontario, London, Ontario, Canada N6A-5C1. 2Ear Institute, University College London, London, UK. ${ }^{3}$ Department of Physiology and Pharmacology, University of Western Ontario, London, Ontario, Canada N6A-5C1.

*Author for correspondence (Dale.Laird@schulich.uwo.ca)
}

Received 20 May 2015; Accepted 8 September 2015
This suggests that each channel type will exhibit some unique features and functions. Connexin 30 (Cx30; also known as GJB6) is specifically expressed in skin keratinocytes (Di et al., 2001), brain astrocytes (Dahl et al., 1996), retinal astrocytes (Mansour et al., 2013) and various inner ear cell types (Forge et al., 2003a). Mutations in the Cx30-encoding gene GJB6 cause skin disease or hearing loss, or a combination of both (Xu and Nicholson, 2013), suggesting an essential role for $\mathrm{Cx} 30$ in these systems.

The connexin life cycle is a dynamic process that leads to the efficient and rapid turnover of gap junction plaques at the cell surface, usually within 1.5-5 h (Laird et al., 1991; Laird et al., 1995; Laing et al., 1997; Beardslee et al., 1998). Other than Cx46, which has been shown to have a slow turnover rate in enucleated lens fibre cells (Jiang et al., 1993), connexins are presumed to have similar life cycles to that of $\mathrm{Cx} 43$ (also known as GJA1) (Laird, 2006). Generally, connexins are co-translationally inserted into endoplasmic reticulum (ER) membranes before trafficking as monomers or oligomers (Das et al., 2009) to the trans-Golgi network where they complete their oligomerization into connexons (Musil and Goodenough, 1993; Vanslyke et al., 2009). Vesicular and tubular post-Golgi carriers transport connexons to the cell surface in a process that, for $\mathrm{Cx} 43$ at least, requires intact microtubules (Thomas et al., 2001; Thomas et al., 2005; Shaw et al., 2007). Many interacting proteins bind to or phosphorylate connexins, such as $\mathrm{Cx} 43$, to regulate localization, gap junction clustering, channel functionality and turnover dynamics (Laird, 2010; Solan and Lampe, 2014). Many of these protein binding/ interacting sites are found within the $\mathrm{C}$-terminal tail of $\mathrm{Cx} 43$, so the question arises as to how smaller connexins with short C-terminal tails, such as Cx26 (also known as GJB2) and Cx30, are regulated in the absence of protein interacting sites. To date, very few studies have investigated the life cycle of $\mathrm{Cx} 30$.

In contrast to $\mathrm{Cx} 43$, some reports have suggested variations in the life cycle of Cx26, and more recently Cx30. Firstly, Cx26 has been suggested to post-translationally insert into ER membranes in cellfree in vitro systems (Ahmad et al., 1999; Zhang et al., 1996) and even directly into plasma membranes (Ahmad and Evans, 2002). However, these findings have not been confirmed in vivo. Secondly, based on their insensitivity to the ER-Golgi transport blocker brefeldin A (BFA), both Cx26 and Cx30 have been suggested to traffic to the cell surface via Golgi-independent pathways (George et al., 1999; Martin et al., 2001; Qu et al., 2009). In contrast, data from our laboratory has shown that Cx26 follows a similar trafficking pathway through the Golgi apparatus, similar to $\mathrm{Cx} 43$ (Thomas et al., 2005). Thirdly, the dependence on intact microtubules for correct trafficking to the cell surface is essential for $\mathrm{Cx} 43$ - which contains binding sites for both tubulin and ZO-1 (Giepmans et al., 2001a,b), but is not necessary for Cx26 targeting in normal rat kidney (NRK) cells and rat mammary tumour BICR$\mathrm{M}_{1} \mathrm{R}_{\mathrm{k}}$ cells (Thomas et al., 2001; Thomas et al., 2005) or $\mathrm{Cx} 30$ in HeLa cells (Qu et al., 2009). In the latter study, Cx30 was shown to 
interact with actin and $\beta$-tubulin, but not the tight junction protein ZO-1, suggesting a novel role for actin-based trafficking/ stabilization of Cx30 gap junctions (Qu et al., 2009).

In this study we have investigated various aspects of the $\mathrm{Cx} 30$ life cycle, with particular focus on the trafficking and stability of $\mathrm{Cx} 30$ at the cell surface. In contrast to what has been reported for $\mathrm{Cx} 26$ previously (George et al., 1999; Martin et al., 2001) and has more recently been suggested for $\mathrm{Cx} 30$ (Qu et al., 2009), we found that Cx30 traffics via the classical secretory pathway through the Golgi apparatus before reaching the cell surface. In comparison with the short 1-5 h half-lives determined for Cx26, Cx32, Cx43 and Cx45 (Fallon and Goodenough, 1981; Traub et al., 1989; Laird et al., 1991; Darrow et al., 1995; Laird et al., 1995; Laing et al., 1997; Beardslee et al., 1998; Thomas et al., 2005), we found that Cx30 has an unusually long half-life at the cell surface. In order to facilitate differential clearing of $\mathrm{Cx} 30$ and $\mathrm{Cx} 43$ from the cell surface we found that these connexins were segregated into distinct regions within the same gap junction plaque. In addition, disrupting the actin and microtubule cytoskeletal networks did not adversely affect the stable nature of $\mathrm{Cx} 30$ plaques at the cell surface, whereas those formed of $\mathrm{Cx} 43$ became less organized and internalized. These features suggest that connexin turnover and life cycles vary markedly between $\mathrm{Cx} 30$ and $\mathrm{Cx} 43$.

\section{RESULTS}

\section{Cx30-GFP dynamics in living cells}

To study Cx30 dynamics in living cells (without the influence of other connexins) Cx30-green fluorescent protein (GFP) was expressed in HeLa cells and its movement, remodelling and clearing from the cell surface was assessed. HeLa cells were efficient in assembling Cx30 gap junction plaques at the cell-cell interfaces (Fig. 1). To assist in determining the dynamic properties of $\mathrm{Cx} 30$ GFP gap junctions, we photobleached three clearly defined plaques (Fig. 1, circles labelled 1, 2 and 3) and assessed their recovery over time. Within the $2 \mathrm{~h}$ and $20 \mathrm{~min}$ recording period, the photobleached plaques were relatively slow to recover and did not fully reach pre-bleach levels; however, GFP fluorescence was visible within the bleached areas ( 1 and 3 ), indicating partial plaque replenishment. Note that the bleached plaque in region 2 did not recover due to separation of the cells. Non-bleached plaques were either very stable or were wholly internalised into a single cell in structures similar in appearance to connexosomes, as has been reported for other connexins (Jordan et al., 1999; Jordan et al., 2001; Piehl et al., 2007). Interestingly, connexosomes were either degraded rapidly and disappeared, or hovered near the cell surface (see arrows, Fig. 1; Movie 1).

\section{Cx30-GFP gap junction plaques are replenished at the outer edge}

To investigate $\mathrm{Cx} 30$ dynamics and gap junction plaque replenishment further, Cx30-GFP plaques between HeLa cells were photobleached (red box, Fig. 2) and fluorescence recovery after photobleaching (FRAP) recorded over a $2 \mathrm{~h}$ period (Fig. 2). Composite images of Cx30-GFP fluorescence (green) and DIC were taken from a $z$-stack plane at the time points indicated in the upper panel of Fig. 2. Z-stacks were also processed into threedimensional (3D) reconstructions for further in-depth FRAP analysis and rotated so that the plaque region was almost en face (bottom panels of Fig. 2 and Movie 2; only Cx30-GFP in green is shown). After only 26 min a faint rim of Cx30-GFP fluorescence was visible around the photobleached region (see arrows in bottom panel of Fig. 2; Movie 2). The rim continued to increase in size and fluorescence until completion of the recording. By the $2 \mathrm{~h}$ time point, the gap junction plaque appeared somewhat similar in fluorescence intensity to that of the prebleached plaque. The accrual of Cx30-GFP in a ring-like structure around the photobleached region suggests that plaque renewal occurs at the outer edge of established plaques.

\section{Cx30 plaques persist at cell-cell interfaces in cultures treated with the ER-Golgi trafficking inhibitor brefeldin A}

Blocking protein transport from the ER to the Golgi apparatus with BFA leads to an accumulation of $\mathrm{Cx} 43$ in the ER and, due to its fast
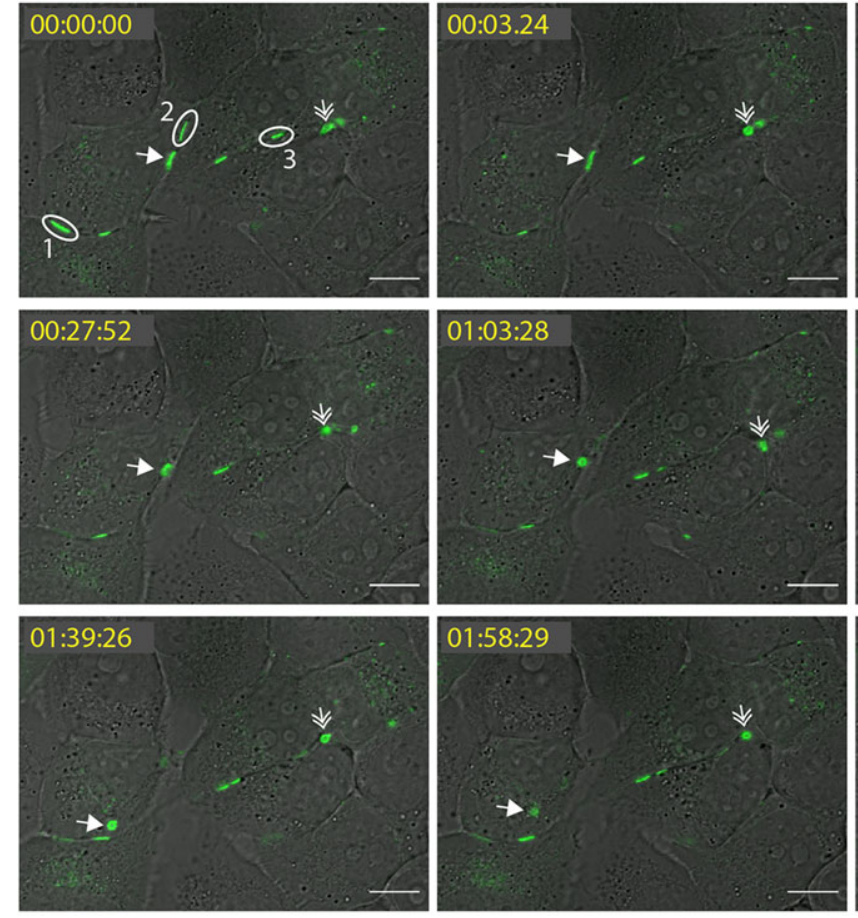
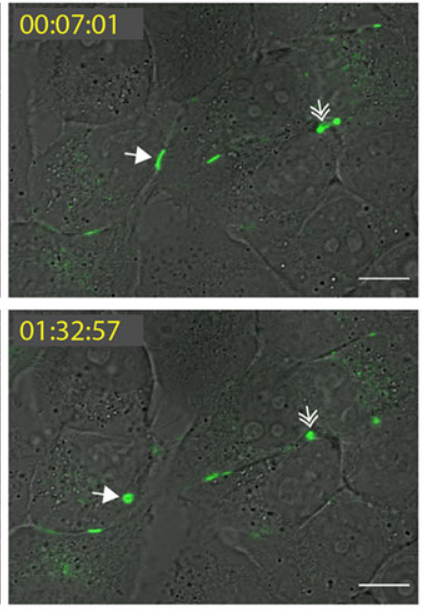

$02: 19: 20$

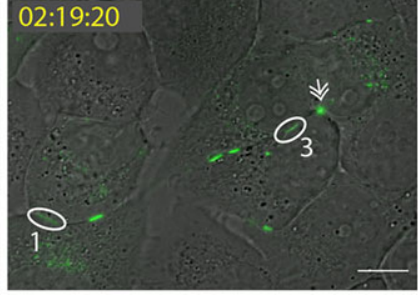

Fig. 1. Live cell time lapse imaging of HeLa cells engineered to express $\mathrm{C} \times 30$ GFP. Gap junction plaques were clearly visible between cells at the $0 \mathrm{~h}$ time point (arrows). Images were acquired every $20 \mathrm{~s}$ and plaques labelled 1, 2 and 3 were photobleached immediately after the $0 \mathrm{~h}$ time point. There was partial fluorescent recovery of the photobleached plaques as evident in the ovals labelled 1 and 3 . A gap junction being internalized and degraded after cell-cell separation is denoted by the filled arrow whereas a connexosome that remained close to the initial junction region and was not degraded during the movie time frame is denoted by a double arrow. Scale bars, $10 \mu \mathrm{m}$. 

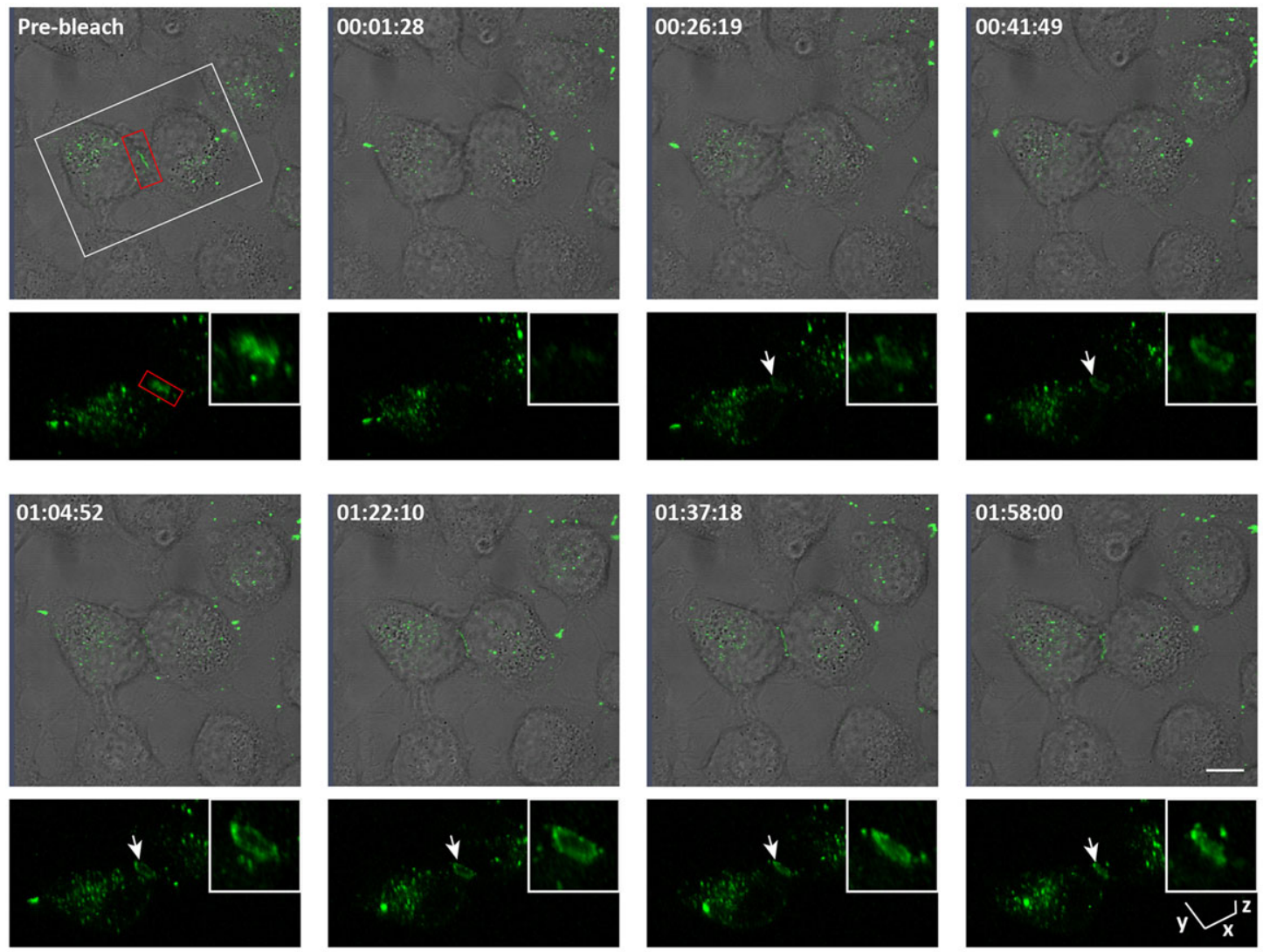

Fig. 2. Cx30 gap junctions are replenished at the plaque edge. Gap junction plaques within HeLa cells expressing Cx30-GFP were photobleached (red box) and its fluorescence recovery recorded in $3 \mathrm{D}$ z-stacks every $20 \mathrm{~s}$ for $2 \mathrm{~h}$. The top panel shows $2 \mathrm{D}$, single-plane, DIC images with GFP fluorescence at various time

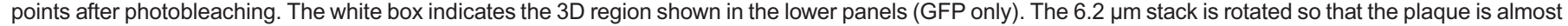
en face (red box, panel 1). Plaque fluorescent replenishment began within 20 min after photobleaching and occurred progressively at the plaque boundary (arrows) and returned to near prebleach fluorescent intensity within $2 \mathrm{~h} .2 \mathrm{D}$ scale bar, $10 \mu \mathrm{m} ; 3 \mathrm{D}$ scale bars: $x, 10 \mu \mathrm{m} ; y, 10 \mu \mathrm{m} ; \mathrm{z}, 6 \mu \mathrm{m}$.

turnover rate, loss of $\mathrm{Cx} 43$ plaques at the cell surface within $6 \mathrm{~h}$ (Laird et al., 1995; Martin et al., 2001; Thomas et al., 2005). We investigated whether Cx30 exhibits similar kinetics in HeLa cells in comparison with $\mathrm{Cx} 26$ and $\mathrm{Cx} 43$. Cx30 gap junction plaque numbers were not noticeably reduced in the presence of BFA, whereas $\mathrm{Cx} 26$ localization was more perinuclear and $\mathrm{Cx} 43$ exhibited a profile resembling the location of the ER (Fig. 3A). Continuous introduction of neurobiotin into a single cell via wholecell patch clamp and subsequent streptavidin detection of neurobiotin spread after $10 \mathrm{~min}$ revealed that BFA greatly reduced coupling in $\mathrm{Cx} 43$ - and $\mathrm{Cx} 26$-expressing cells $(P<0.001)$ but not Cx30-expressing cells $(P=0.656$, Fig. $3 \mathrm{~B})$. The resistance of $\mathrm{Cx} 30$ gap junctions to clearing from the cell surface in the presence of BFA, even after prolonged treatments of $18 \mathrm{~h}$, was further confirmed in Cx30-expressing rat epidermal keratinocytes (REKs) (Fig. 4A) and NRKs (Fig. 4B). In many REKs, Cx30 accumulated in the ER, as determined by co-localization with the ER marker protein disulphide isomerase (PDI; green, inset in Fig. 4A), but still retained gap junction plaques (arrows, Fig. 4A). This indicates that when ER-to-Golgi transport is blocked, Cx30 is unable to exit the ER along the classical secretory pathway.

\section{Cx30 trafficking to the cell surface is inhibited by a Sar1 dominant-negative mutant}

Although Cx30 plaques were persistent at the cell surface in the presence of BFA, we could not rule out the possibility of a direct Golgi-independent trafficking pathway playing a role in replenishing the gap junction plaques, as has been previously suggested (Qu et al., 2009). To address this possibility we coexpressed Cx43 or Cx30 together with a DsRed2-tagged dominantnegative mutant (H79G) form of Sarl (secretion-associated RASrelated protein 1) to prevent protein transport to the cis-Golgi, as we have reported previously (Thomas et al., 2005; Bhalla-Gehi et al., 2010) (Fig. 5A,B). Wild-type Sar1 was localized to perinuclear regions where its expression had no effect on $\mathrm{Cx} 43$ gap junction plaque formation (Fig. 5A). Upon Sar $1^{\mathrm{H} 79 \mathrm{G}}$ expression $\mathrm{Cx} 43$ exhibited an ER-like pattern and appeared to lose gap junction plaques at the cell surface (Fig. 5A). In a similar fashion, REKs co-expressing Cx30 and wild-type Sar1 had no discrepancies in their ability to form gap junction plaques, whereas Sar1 ${ }^{\mathrm{H} 79 \mathrm{G}}$ caused Cx30 to be retained in an ER-like pattern and led to a loss of gap junction plaques between cells (Fig. 5B). These results suggest that $\mathrm{Cx} 30$ is transported through the Golgi apparatus.

\section{Cx30 protein has an extended half-life compared with Cx43 in keratinocytes}

To assess the relative half-life of $\mathrm{Cx} 30$, REKs that co-expressed $\mathrm{Cx} 30$ and $\mathrm{Cx} 43$ were treated with the translational inhibitor cycloheximide (CHX) for up to $8 \mathrm{~h}$ and connexin content was evaluated by immunofluorescent labelling and western blots (Fig. 6A,B). While Cx43 levels were quickly reduced (Fig. 6A,B), $\mathrm{Cx} 30$ levels remained relatively unchanged for up to $8 \mathrm{~h}$ of $\mathrm{CHX}$ treatment, suggesting that $\mathrm{Cx} 30$ has a prolonged half-life compared with $\mathrm{Cx} 43$. 
A

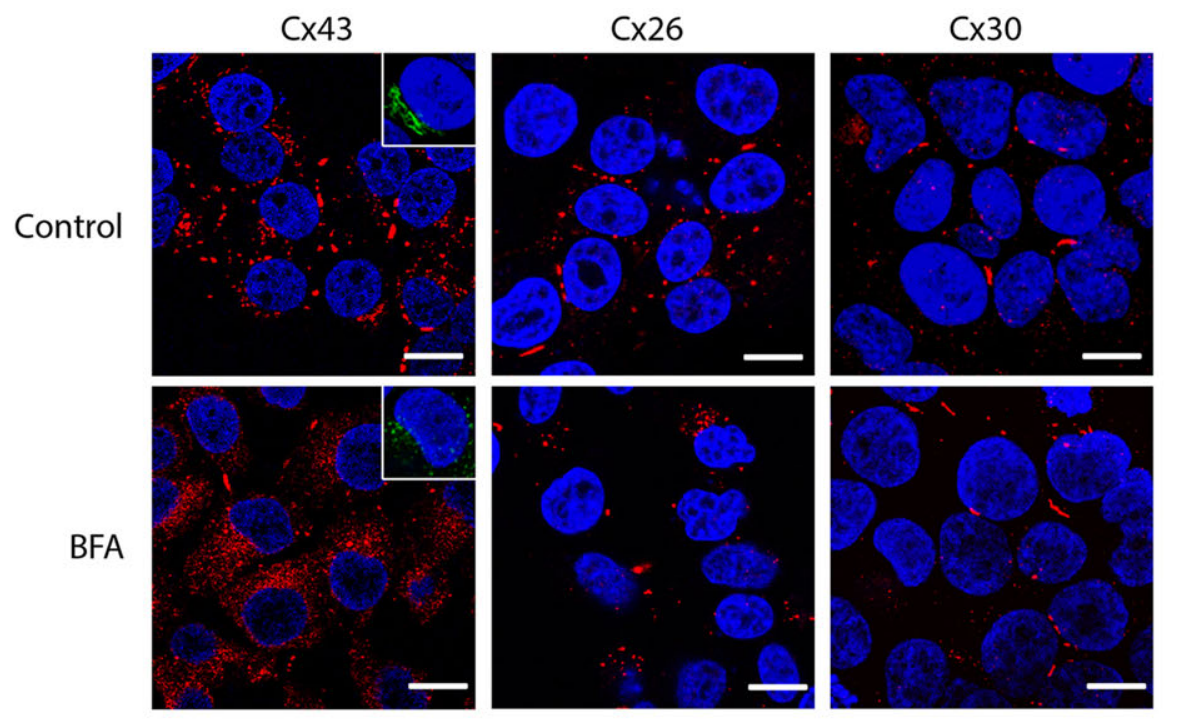

B
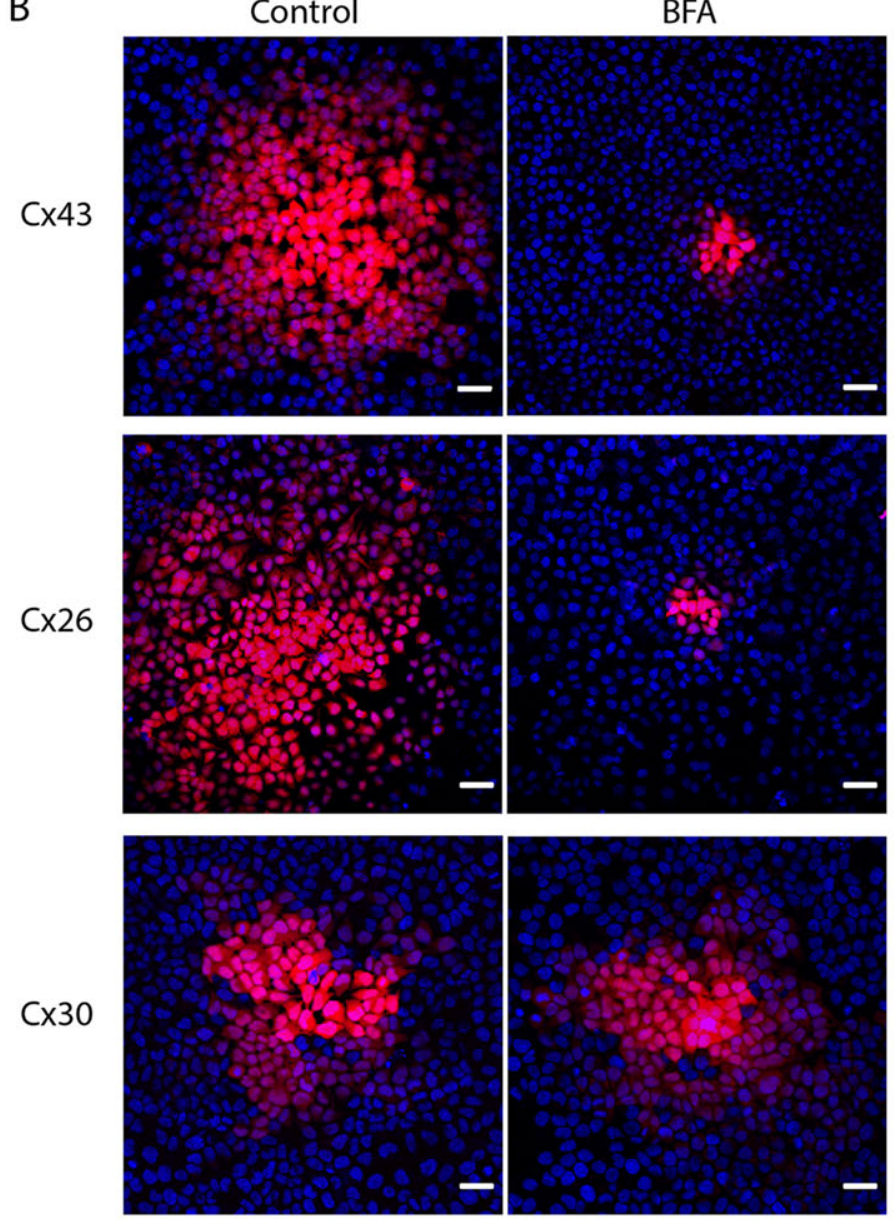
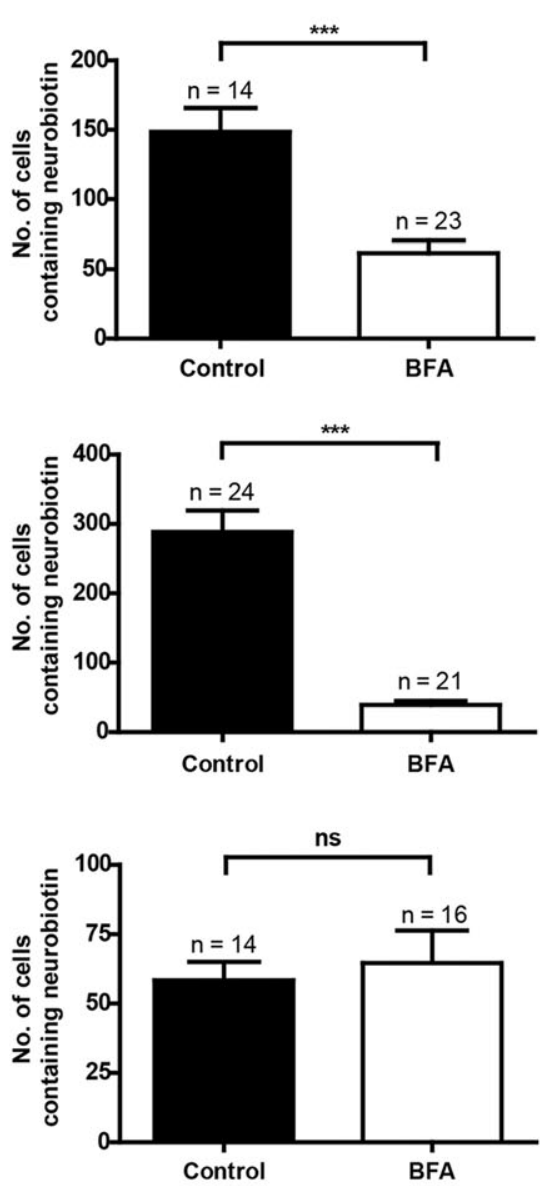

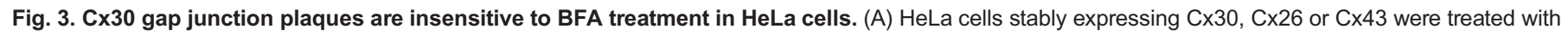
BFA for $7 \mathrm{~h}$ to disrupt ER-to-Golgi transport, as indicated by the dissociated Golgi apparatus (inset, green). Cx43 localization was mostly intracellular after

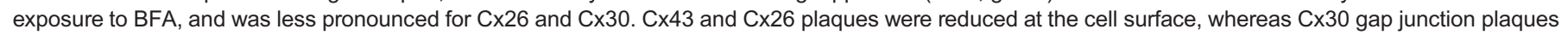

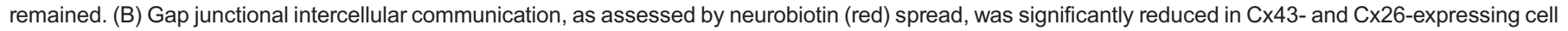
lines after BFA treatment; however, there was no significant difference in the extent of transfer in Cx30-expressing cells. Scale bars, $10 \mu \mathrm{m}(\mathrm{A})$; $50 \mu \mathrm{m}(\mathrm{B})$. $P$-values were calculated using Student's $t$-test. ${ }^{* *} P<0.001$; ns, not significant.

To further assess the prolonged half-life for Cx30, REKs coexpressing $\mathrm{Cx} 43$ and $\mathrm{Cx} 30$ were treated with BFA for $7 \mathrm{~h}$ before separating the cell lysate into Triton-soluble (non-plaque pool) or
Triton-insoluble (plaque pool) fractions. In control cells, immunoblot analysis revealed similar levels of total $\mathrm{Cx} 43$ in both the soluble and insoluble fractions (Fig. 7A,B), whereas the 
A
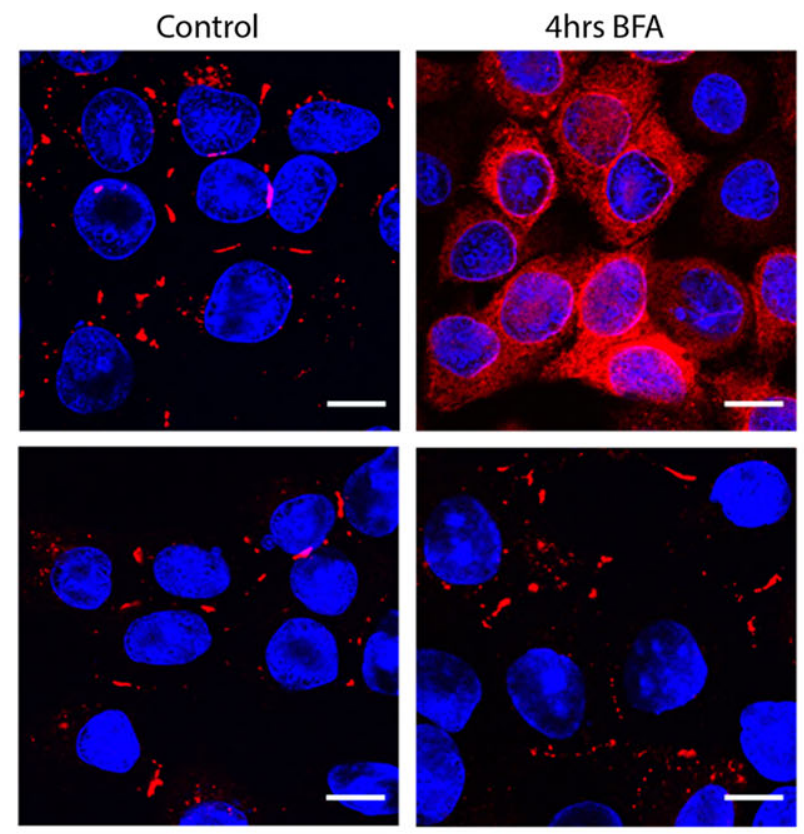

B
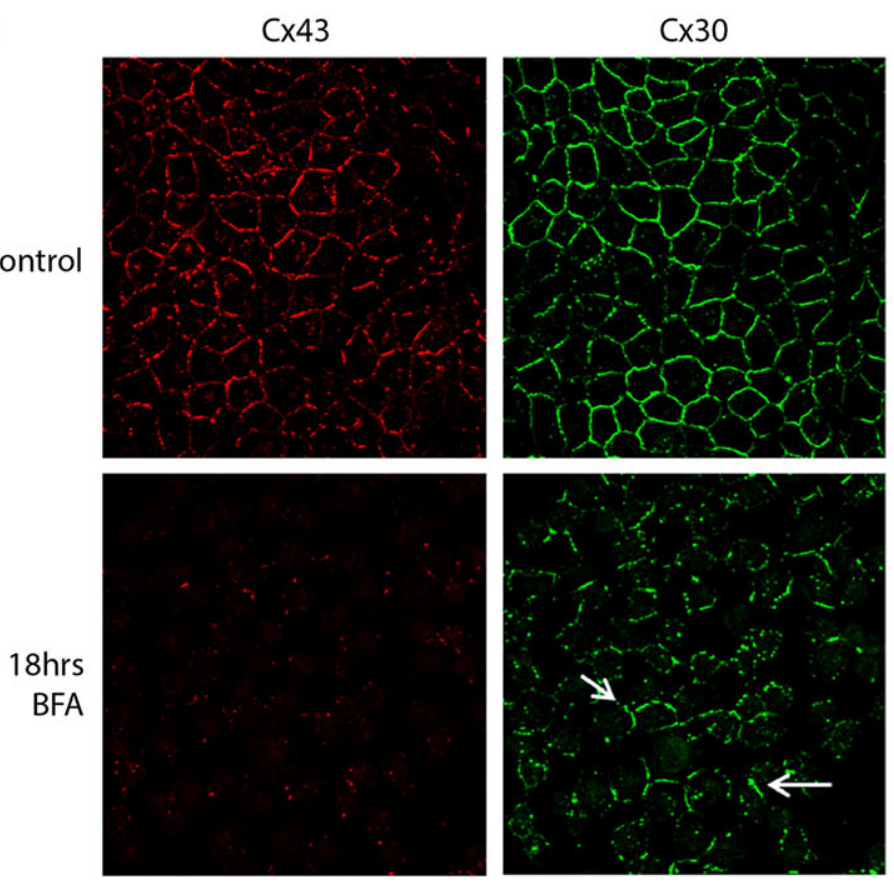
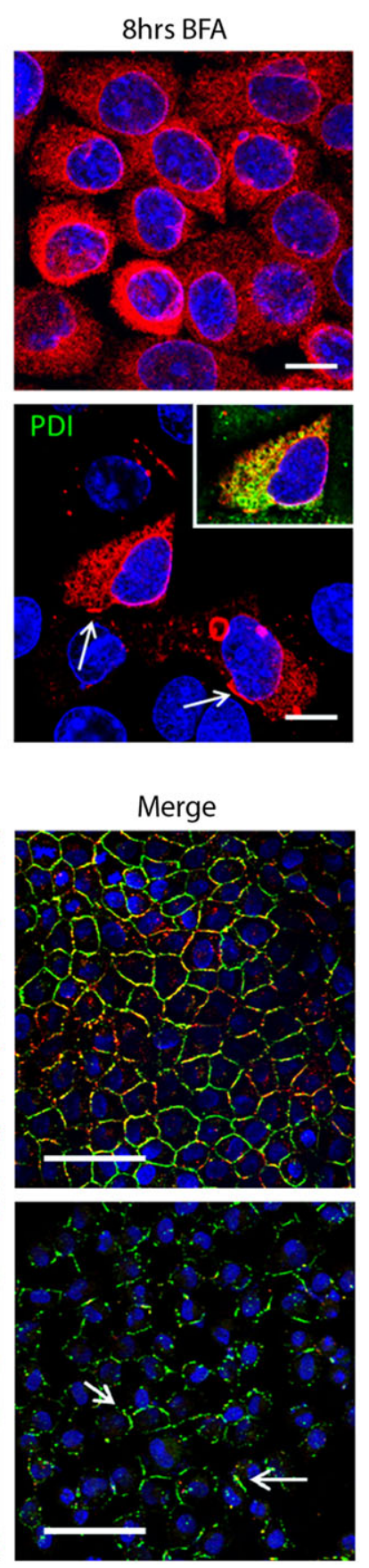

Fig. 4. Cx30 gap junction plaques are insensitive to BFA treatment in connexin-expressing cell lines.

(A) REKs expressing Cx43 (upper panel, red) or Cx30 (lower panel, red) were treated with BFA for up to $8 \mathrm{~h}$. A this point $\mathrm{C} \times 30$ plaques remained at the cell surface (arrows) despite $\mathrm{C} \times 30$ accumulating in the ER, as indicated by co-localization with the ER marker PDI (green, inset), whereas Cx43 was completely localized inside the cell.

(B) NRKs co-expressing Cx30 and Cx43 were exposed to BFA for up to $18 \mathrm{~h}$ and double immunolabelled with monoclonal mouse anti-Cx43 (red) and polyclonal rabbit anti-Cx30 (green) antibodies. Even at $18 \mathrm{~h}$ strong cell-surface, plaque-like staining of Cx30 was evident (arrows), whereas Cx43 was virtually absent from the cell surface. Scale bars: $10 \mu \mathrm{m}(\mathrm{A})$, $50 \mu \mathrm{m}(\mathrm{B})$. phosphorylated species $\left(\mathrm{P}_{1} / \mathrm{P}_{2}\right)$ were more abundant in the insoluble fraction (Fig. 7A,C) as expected, since these phosphorylation states usually reflect mature gap junction plaques (Lampe and Lau, 2000). Cx30 was more abundant in the insoluble fraction of control cells (Fig. 7A,D). After BFA treatment, the soluble fractions were not significantly different from the controls for both total $\mathrm{Cx} 43$ (Fig. 7B, $P=0.236$ ) and $\mathrm{Cx} 30$ (Fig. 7D, $P=0.894$ ), whereas levels of $\mathrm{Cx} 43$ in the insoluble fractions decreased significantly $(P<0.001$, Fig. 7B,C). Interestingly, insoluble Cx30 protein levels were not significantly different after BFA treatment (Fig. 7D). The ratio of insoluble protein after BFA treatment to control insoluble protein revealed a significant reduction of the total $(P<0.001)$ and phosphorylated $(P<0.001) \mathrm{Cx} 43$ species in comparison with $\mathrm{Cx} 30$ (Fig. 7E). These results further suggest that $\mathrm{Cx} 30$ exhibits an extended half-life projected to be $>12 \mathrm{~h}$ (estimated from the average reduction in intensity over $8 \mathrm{~h}$, to the point where the intensity would be predicted to have dropped by $50 \%$ from the starting value) when assembled into gap junction plaques.

\section{Disruption of cytoskeletal elements does not destabilize Cx30 gap junctions}

To determine the effect of disrupting cytoskeletal elements on Cx30-containing gap junction plaques at the cell surface, REKs expressing $\mathrm{Cx} 30$ and $\mathrm{Cx} 43$ were treated with cytochalasin B (cytoB) to disrupt actin microfilaments (Fig. S1) or nocodazole to depolymerize microtubules (Fig. S2). Treatment with cytoB initiated a reduction in filamentous actin and led to a reduction in cortical actin staining at the cell border; however, there was no discernible change in $\mathrm{Cx} 30$ gap junction plaques even after $10 \mathrm{~h}$ of treatment (Fig. S1). In contrast, Cx43 puncta at cell-cell 
A
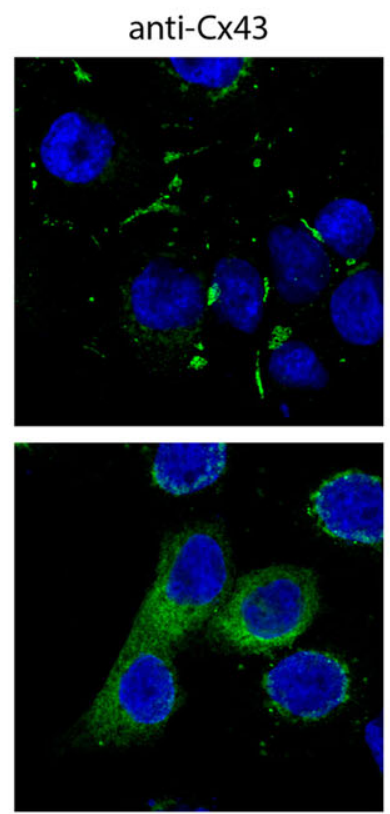

B
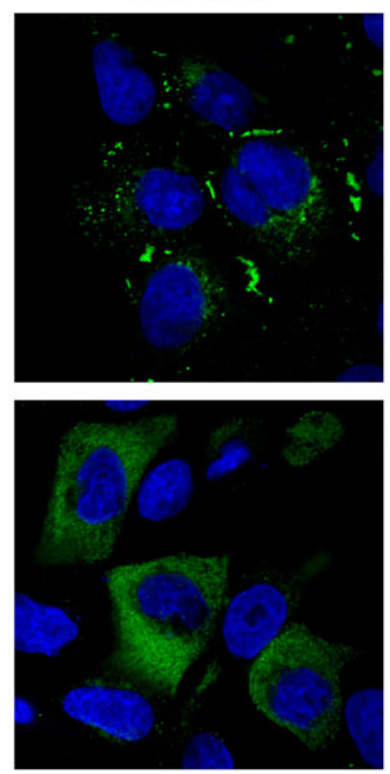

Sar1-DsRed2
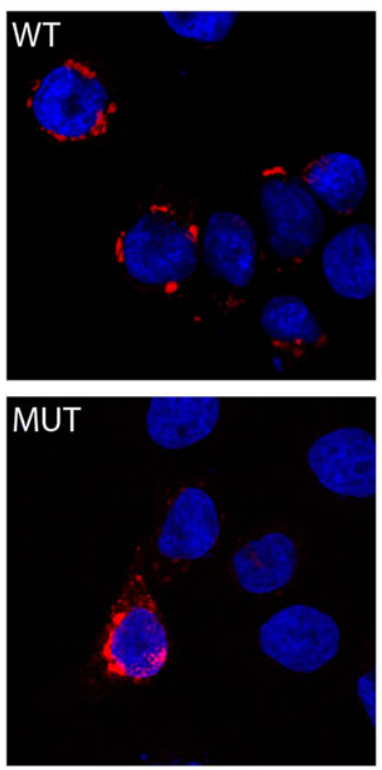

Sar1-DsRed2
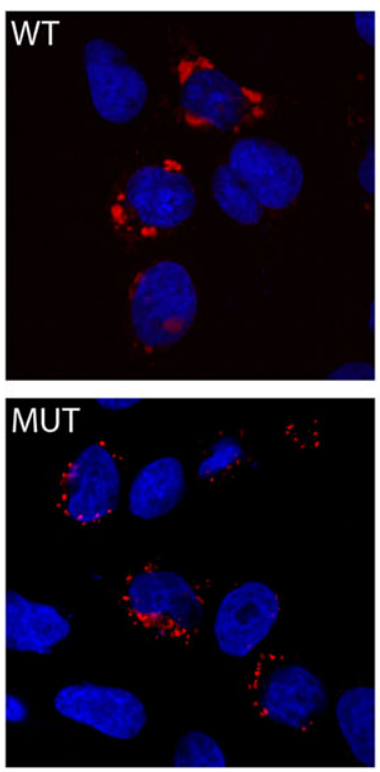
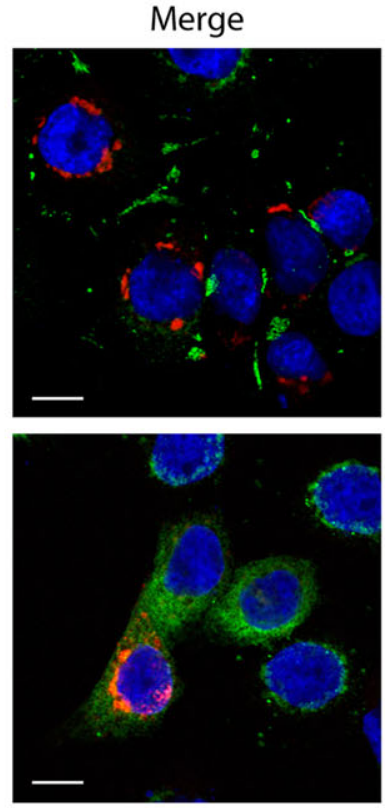

Merge
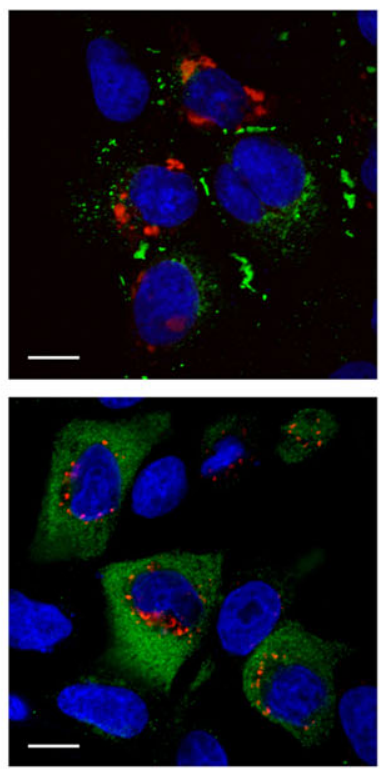

Fig. 5. Expression of a dominant-negative Sar1 mutant inhibits $\mathrm{Cx} 30$ trafficking to the cell surface. REKs expressing Cx43 or Cx30 together with Sar1-DsRed2 (WT) or Sar1 ${ }^{\text {H79G }}$-DsRed2 (MUT) were immunolabelled for $\mathrm{C} \times 43(\mathrm{~A})$ or $\mathrm{C} \times 30(\mathrm{~B})$.

Sar1-DsRed did not disrupt trafficking of $\mathrm{C} \times 43$ or $\mathrm{C} \times 30$ to the cell surface, whereas Sar $1^{\mathrm{H} 79 \mathrm{G}}$ DsRed2 led to retention of both connexins in the ER. Scale bars, $10 \mu \mathrm{m}$. interfaces $(0 \mathrm{~h})$ appeared reduced after $2 \mathrm{~h}$ of cytoB treatment and $\mathrm{Cx} 43$ localization was more intracellular. This suggests that actin filaments do not play a role in stabilizing Cx30 gap junctions. Treatment with nocodazole completely depolymerized microtubules within $2 \mathrm{~h}$ as assessed by $\beta$-tubulin staining (Fig. S2). This had no detrimental effect on Cx30 gap junctions even after $10 \mathrm{~h}$ of treatment while many cell surface $\mathrm{Cx} 43$ plaques were lost after only $2 \mathrm{~h}$ of treatment.

\section{Cx30 and Cx43 segregate and partition into distinct regional domains within the same gap junction plaques}

Since $\mathrm{Cx} 30$ and $\mathrm{Cx} 43$ can be temporally co-expressed within keratinocytes in vivo we wanted to assess whether they fully intermixed within a gap junction plaque, or whether they partitioned into separate regions of the same plaque. REKs expressing Cx30GFP and immunolabelled for $\mathrm{Cx} 43$ revealed that these connexins were localized to the same plaques (Fig. 8A); however, most of the
Cx43 puncta were distinct from $\mathrm{Cx} 30-\mathrm{GFP}$ plaque regions (Fig. 8B-D). Next we used immunolabelling to examine the localization pattern of $\mathrm{Cx} 30$ and $\mathrm{Cx} 43$ in NRKs (Fig. 8E). High resolution $z$-stacks that were deconvolved into $3 \mathrm{D}$ images and rotated on a side angle revealed that $\mathrm{Cx} 30$ and $\mathrm{Cx} 43$ segregated into distinct, non-overlapping domains (Fig. 8F,G). In comparison, cells expressing both Cx30-GFP and Cx26-red fluorescent protein (RFP) had over-lapping expression patterns (Fig. 8H-K), which is indicative of heteromeric or heterotypic gap junction configurations, as described previously (Marziano et al., 2003).

\section{DISCUSSION}

Cx30 is a critical connexin in hearing and skin homeostasis. We and others have shown that loss-of-function $\mathrm{Cx} 30$ gene mutations can lead to severe deafness and devastating skin diseases or both (Grifa et al., 1999; Essenfelder et al., 2004; Schutz et al., 2010; Wang et al., 2011; Berger et al., 2014; Bosen et al., 2014). Yet the cellular life 
A
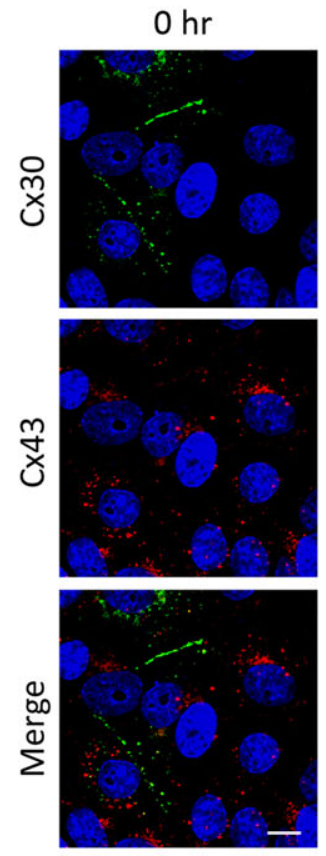

$4 \mathrm{hr}$
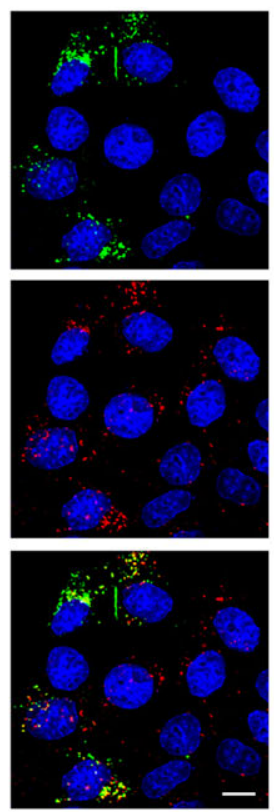

$6 \mathrm{hr}$
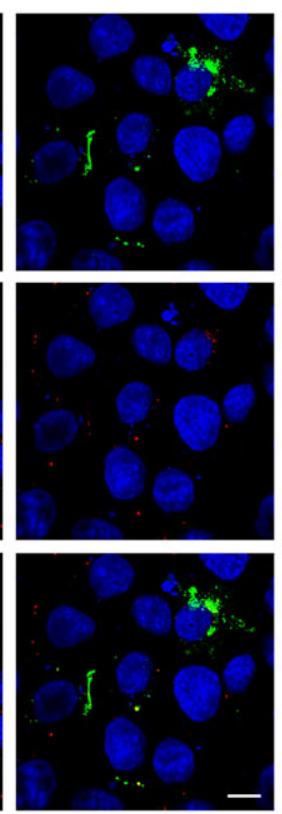

$8 \mathrm{hr}$
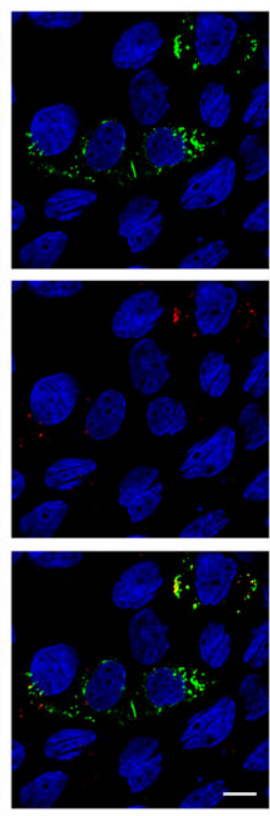

Fig. 6. Cx30 is a long-lived connexin. REKs expressing Cx43 and engineered to express Cx30 were exposed to $10 \mu \mathrm{g} / \mathrm{ml}$ cycloheximide (CHX) for up to $8 \mathrm{~h}$. Immunofluorescent labelling (A) and western blotting of total protein lysates (B) revealed a steady decline in $\mathrm{Cx} 43$ expression, whereas $\mathrm{C} \times 30$ localization and expression levels remained relatively constant during up to $8 \mathrm{~h}$ of $\mathrm{CHX}$ treatment. Scale bars, $10 \mu \mathrm{m} .{ }^{* *} P<0.001$.
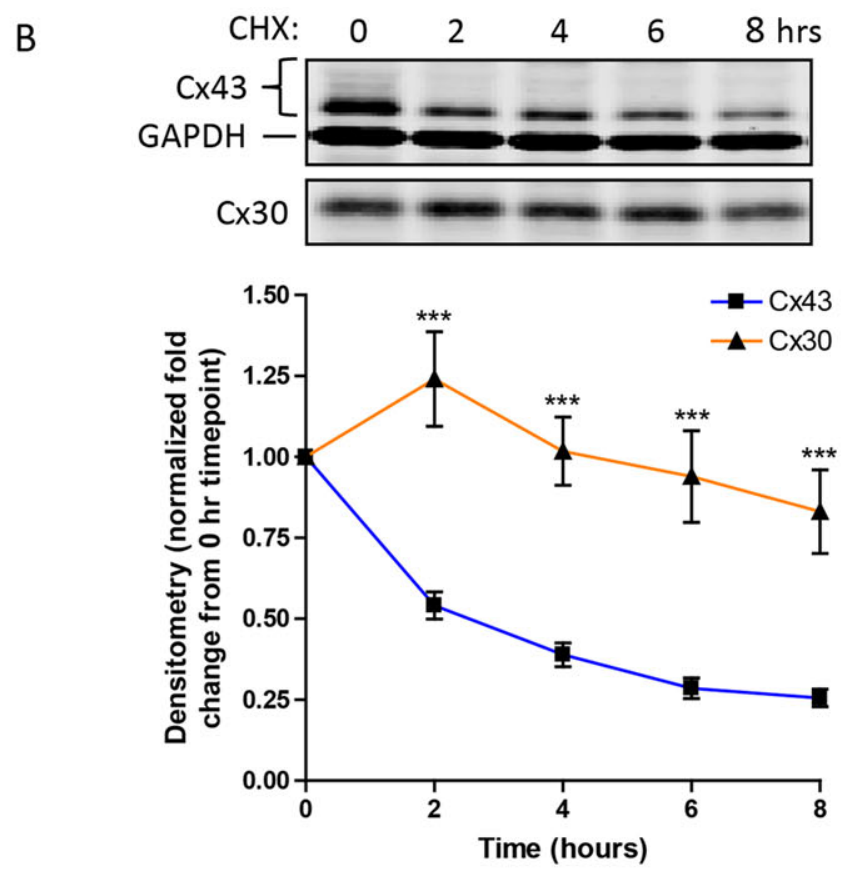

cycle of this connexin remains poorly studied. Insights into its normal life cycle may help determine how it serves essential roles in both hearing and epidermal function. In this study we provide compelling evidence in multiple cell types, including keratinocytes, that $\mathrm{Cx} 30$ exhibits a prolonged life in gap junctions (half-life $>12 \mathrm{~h}$ ) where it acts to maintain a stable level of GJIC. Thus Cx30 is a novel connexin deviating from the short half-life of most other connexins (half-lives of 1-5 h) that are expressed in cells that actively progress through the cell cycle (Fallon and Goodenough, 1981; Traub et al., 1989; Laird et al., 1991; Darrow et al., 1995; Laird et al., 1995; Laing et al., 1997; Beardslee et al., 1998; Thomas et al., 2005). Our studies suggest that $\mathrm{Cx} 30$ may acquire a prolonged half-life compared with $\mathrm{Cx} 43$ by segregating into distinct subdomains within gap junction plaques although it can fully intermix with the highly homologous Cx26. Like many, if not all connexins studied to date, $\mathrm{Cx} 30$ follows the classical secretory pathway by trafficking in a COPII-dependent manner through the Golgi apparatus. Distinct from $\mathrm{Cx} 43$, we also show that the stability of Cx30 gap junction plaques are not affected by cytoskeletal-disrupting drugs, whereas other aspects of the life cycle, such as gap junction renewal and internalization via connexosomes, appear similar to other connexins.

Cx30 dynamics were assessed using time-lapse imaging of live cells expressing Cx30-GFP in connexin-deficient HeLa cells. We have previously shown that the presence of GFP does not affect the ability for $\mathrm{Cx} 30$ to traffic to the cell surface and form functional gap junction channels and hemichannels (Berger et al., 2014). While a few Cx30 plaques were dynamic, splitting up and 
A

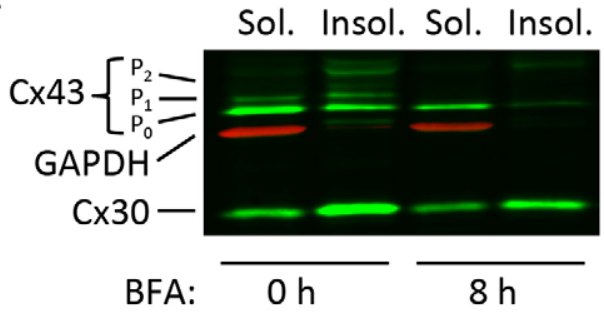

B

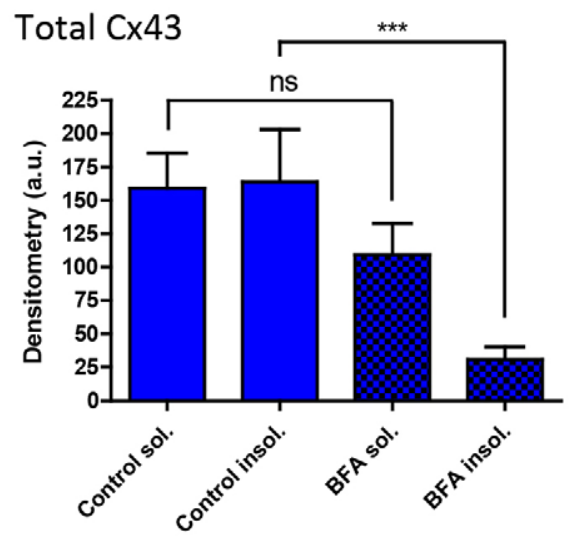

D

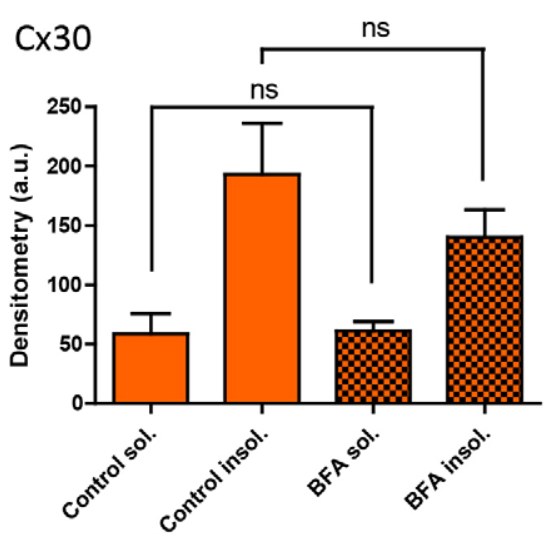

C

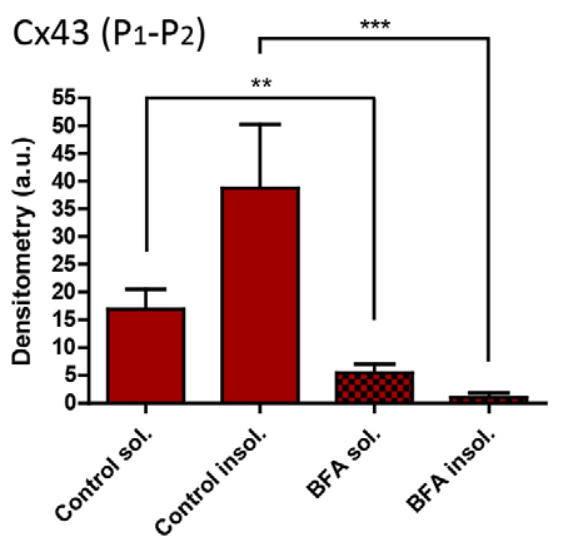

$E$

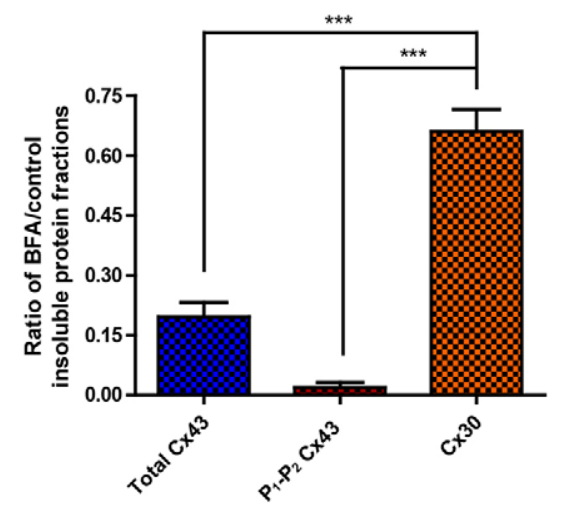

Fig. 7. Cx30 remained in a Tritoninsoluble fraction after BFA treatment. Control or BFA-treated REKs expressing $\mathrm{C} \times 30$ and $\mathrm{C} \times 43$ were separated into Triton $\mathrm{X}$-100-soluble or -insoluble fractions and analysed by western blot (green, A). GAPDH (red) was used as a control counterstain and was only detected in the soluble fractions (A). The levels of total Cx43 (B), phosphorylated Cx43 (C), total Cx30 (D) and the ratio of BFA to control insoluble fractions $(E)$ were quantified from three independent experiments. ${ }^{*} P<0.01$; ${ }^{* * *} P<0.001$; ns, not significant. P0, P1 and $\mathrm{P} 2$, phosphorylated species of $\mathrm{C} \times 43$. rejoining again on numerous occasions, most plaques were immobile and stable at the cell surface. This could, however, be due to the presence of an enhanced GFP (EGFP) tag at the $\mathrm{C}$-terminus that may reduce $\mathrm{Cx} 30$ fluidity in the plasma membrane (Stout et al., 2015). In some instances, such as when cells were migrating or dividing, whole Cx30-GFP plaques were internalized into connexosome-like structures, as has been reported for gap junction endocytosis previously (Jordan et al., 2001; Gaietta et al., 2002; Piehl et al., 2007; Leithe et al., 2012). Interestingly, connexosomes appeared to separate into two groups: some that were rapidly internalized and likely to be degraded, and others that remained in close proximity to the cell-cell border throughout the duration of the movie $(\sim 2 \mathrm{~h})$. FRAP experiments revealed that, similar to $\mathrm{Cx} 43$ gap junctions (Gaietta et al., 2002; Lauf et al., 2002; Falk et al., 2009), Cx30 gap junction plaques were replenished from the outer edge as older channels remained sequestered to the inner aspects of the plaques. Together, live cell examination of $\mathrm{Cx} 30$ gap junctions revealed that they are slow to turnover but when they do, they appear to follow the well-studied connexosome internalization pathway denoted by Cx43 (Jordan et al., 2001; Gaietta et al., 2002; Piehl et al., 2007; Leithe et al., 2012). Furthermore, $\mathrm{Cx} 30$ gap junction plaque replenishment at the cell surface appears to be identical to $\mathrm{Cx} 43$ gap junctions (Gaietta et al., 2002; Lauf et al., 2002) in that new channels are sequestered to the outer edges of the plaques while older channels form the core of the plaque.

A report by $\mathrm{Qu}$ and colleagues ( $\mathrm{Qu}$ et al., 2009) suggested that Cx30 could traffic to the cell surface via a Golgi-independent pathway in HeLa cells. This was also previously suggested for Cx26 in HeLa and COS-7 cells (Martin et al., 2001); however, we found that this was not the case for $\mathrm{Cx} 26$ in rat mammary tumour $\left(\right.$ BICR-M1R $\mathrm{k}_{\mathrm{k}}$ ) or NRK cell lines (Thomas et al., 2005). In the present study, we concluded that $\mathrm{Cx} 30$ was routed through the classical secretory pathway in multiple cell types including keratinocytes based on: (1) its accumulation in a merged ER-Golgi compartment upon long-term treatment with BFA, (2) co-localization with resident markers of the ER in long-term BFAtreated cells and (3) accumulation in the ER compartment upon 

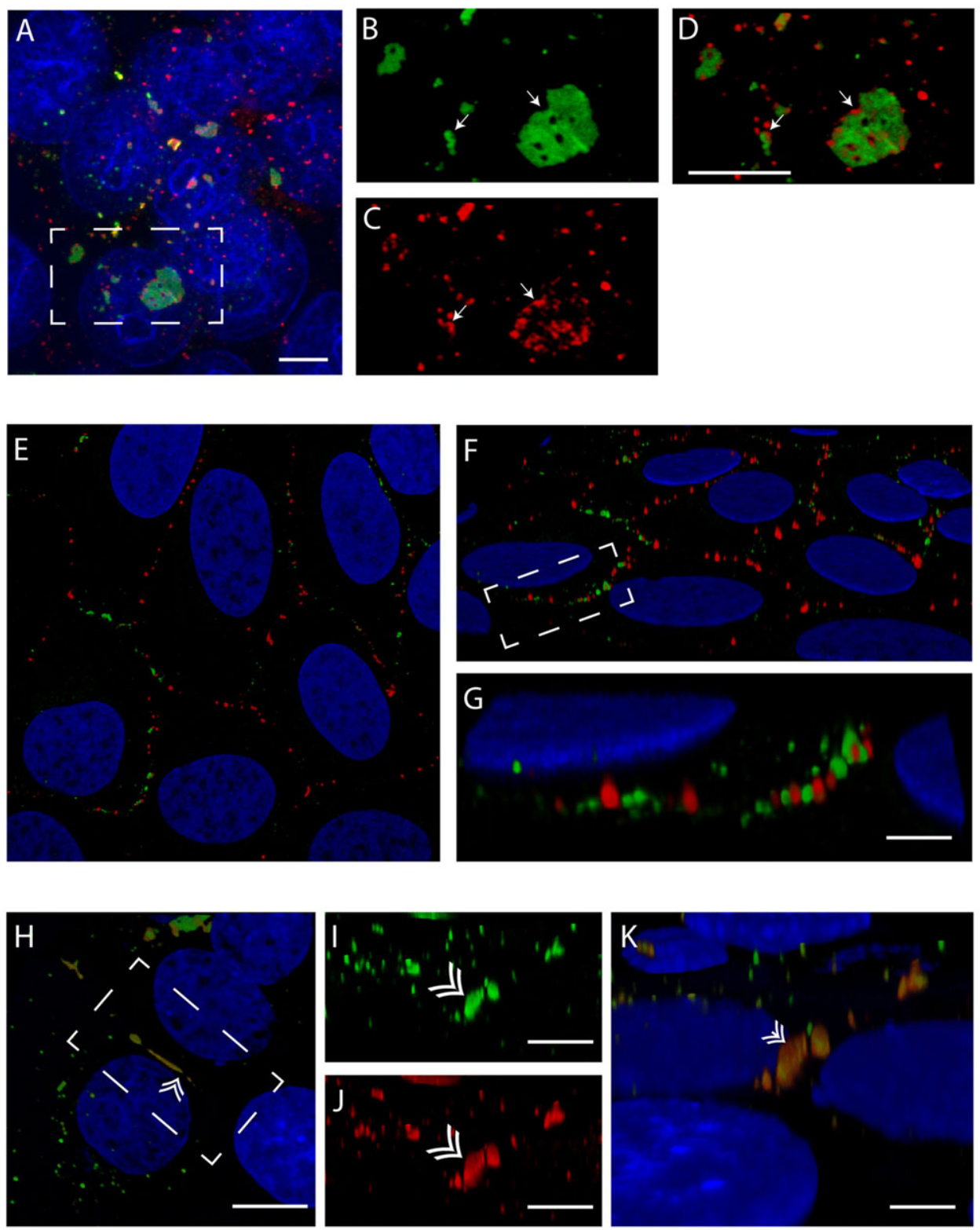

Fig. 8. $\mathrm{C} \times 30$ and $\mathrm{C} \times 43$ segregate into distinct domains when co-expressed in the same cell. (A) An en face view of a large Cx30-GFP plaque (green) is shown between overlapping REKs stained for Cx43 (red). (B-D) Magnified image from boxed region shows that Cx30-GFP and Cx43 were in close proximity but remained distinct and did not co-localize (arrows). (E-G) Untagged Cx30 (green) and Cx43 (red) are also distinct from each other in NRK cells. The image in $F$ is a $3 \mathrm{D}$ deconvoluted image made from $\mathrm{E}$ with the boxed region shown in higher magnification in G. Note the non-overlapping localization of $\mathrm{C} \times 30$ and $\mathrm{C} \times 43$ at the cell surface. (H-K) Cx30-GFP and Cx26-RFP (red) co-localized in the same gap junction plaque in REKs. An overhead projection is shown in $\mathrm{H}$ and the boxed region magnified and rotated in the subsequent panels (I-K). The plaque (double arrow) in this instance showed strong co-localization for Cx30-GFP and Cx26-RFP. Scale bars, $10 \mu \mathrm{m}(\mathrm{A}), 5 \mu \mathrm{m}$ (B-D and $\mathrm{H}$ ), $2 \mu \mathrm{m}$ ( $\mathrm{G}$ and $\mathrm{I}-\mathrm{K}$ ). disruption of the Sar1-dependent protein transport pathway. Sar1 is a small GTPase that recruits components of the coat protein complex II (COPII) to the ER membrane in its active GTP-bound form, whereas the mutant $\mathrm{Sar}^{\mathrm{H} 79 \mathrm{G}}$ used in this study is unable to hydrolyse GTP to GDP and thus prevents Cx30 cargo-carrying vesicles from being transported to the Golgi apparatus. These data support a role for COPII-mediated transport of $\mathrm{Cx} 30$ vesicles along the secretory pathway. Thus whether $\mathrm{Cx} 30$ is expressed in reference cell types such as HeLa or NRK cells or expressed in physiologically relevant keratinocytes, it is routed through the Golgi apparatus to the cell surface. Trafficking of $\mathrm{Cx} 30$ to or from the cell surface or the stability of pre-existing Cx30 gap junction plaques appeared to be unaffected by disrupting the microfilament or microtubule cytoskeletons. As previously demonstrated (Thomas et al., 2005) and shown here, Cx43 trafficking and plaque status is dramatically affected by the loss of microtubule integrity, whereas Cx26 trafficking is not dependent on intact microtubule networks. These data suggest that $\mathrm{Cx} 43$ assembly is more dependent on microtubules than either Cx26 (Thomas et al., 2001; Thomas et al., 2005) or Cx30. This may not be unexpected as the known tubulin binding site in the C-terminal tail of $\mathrm{Cx} 43$ (Giepmans et al., 2001a,b) is lacking in both Cx26 and Cx30.

Once assembled into a gap junction, we found that $\mathrm{Cx} 30$ has an unexpectedly long half-life $(>12 \mathrm{~h})$ when directly compared with $\mathrm{Cx} 43$, which has been well documented to have a short half-life of 1-5 h in vitro (Laird et al., 1991; Darrow et al., 1995; Laird et al., 1995; Laing et al., 1997) and in vivo (Fallon and Goodenough, 1981; Beardslee et al., 1998). Several comparative experiments with cells expressing or co-expressing both $\mathrm{Cx} 43$ and $\mathrm{Cx} 30$ suggested that it was the fully assembled $\mathrm{Cx} 30$ gap junction plaques that were long lived as opposed to a possible population of $\mathrm{Cx} 30$ hemichannels. Firstly, Cx30-expressing cells retained high levels of GJIC even after prolonged BFA treatment. Secondly, Cx30 gap junction localization was relatively unaffected by even long BFA treatment times. Thirdly, Cx30 remained in a Triton X-100insoluble pool after BFA treatment. Finally, total Cx30 clearing from the cell surface was highly delayed when cells were treated with the protein synthesis inhibitor cycloheximide. These results indicate that $\mathrm{Cx} 30$ has unique long-lived properties at the cell surface. This property was previously thought to be restricted to lens 
gap junctions consisting of mammalian Cx46 (Jiang et al., 1993) or chick Cx56 (Berthoud et al., 1999) in enucleated fibre cells, where they maintain the metabolic homeostasis of the lens (Slavi et al., 2014). This leads to the question: why would $\mathrm{Cx} 30$ need to have an extended half-life at the cell surface when most other connexins are designed to turn over rapidly?

Firstly, the long half-life of $\mathrm{Cx} 30$ gap junctions may partially explain how Cx30 forms some of the largest-sized gap junction plaques in the vertebrate body (Forge et al., 2003a). In the inner ear, these large $\mathrm{Cx} 30$ gap junction plaques are found between supporting cells within the avascular organ of Corti (Sun et al., 2005; Jagger and Forge, 2006), which plays a key role in $\mathrm{K}^{+}$ buffering and metabolite transfer (Jagger and Forge, 2014). Therefore, large gap junction plaques may be crucial for maintaining homeostasis by maximizing cell-cell transfer of metabolites and nutrients (Chang et al., 2008). In addition, longlived Cx30 gap junction plaques may play an important physiological role in the skin. Cx30 is abundantly expressed in the stratum granulosum, the most differentiated living keratinocyte layer (Di et al., 2001; Churko and Laird, 2013). As keratinocytes terminally differentiate in an avascular environment they lose their intracellular components and establish a calcium gradient, which becomes critical for epidermal health (Menon et al., 1985; Adams et al., 2012). Interestingly, the lens is also an avascular organ (where Cx46 and chick Cx56 have long half-lives) that requires stable gap junctions to maintain the unique microcirculatory system of the lens (Mathias et al., 2010). This suggests that long-lived, large gap junction plaques may be essential for nutrient transfer through GJIC as a compensatory mechanism for tissues that have no direct vascularization.

Secondly, in vivo $\mathrm{Cx} 30$ expression in mammals appears to be limited to quiescent cell types or cells undergoing terminal differentiation. Evidence for this can be found in skin where Cx30 is expressed in terminally differentiated keratinocytes both in human (Di et al., 2001; Richard, 2003; Churko and Laird, 2013) and murine (Coutinho et al., 2003; Kretz et al., 2003) epidermis, in non-proliferating astrocytes within the brain (Kunzelmann et al., 1999) and retina (Mansour et al., 2013), in cochlear supporting cells (Lowenheim et al., 1999; Chen et al., 2003) and mature lateral wall fibrocytes that have become quiescent. In addition, Cx30 is linked to differentiation of mammary gland cells during lactation (Talhouk et al., 2005) and to calcium-induced differentiation of corneal cells (Shurman et al., 2005). These findings might suggest that long-lived $\mathrm{Cx} 30$ plaques are preferentially expressed in quiescent cells or cells undergoing terminal differentiation, perhaps to reduce the burden of constant gap junction renewal and thus permit energy conservation, whilst retaining gap junctional intercellular communication.

Thirdly, in addition to gap junctions mediating intercellular communication, they have been proposed to play a role in cell-cell adhesion (Elias et al., 2007; Falk et al., 2012), which might impact upon processes such as wound healing. For example, in wounded skin, up-regulation of $\mathrm{Cx} 30$ and $\mathrm{Cx} 26$ in all epidermal keratinocyte layers, and a concomitant decrease in $\mathrm{Cx} 43$ at the wound edge, are proposed to co-ordinate the keratinocyte wound healing response (Coutinho et al., 2003; Churko and Laird, 2013). In the damaged cochlea, Cx30 is also important for coordinating a wound healing response after sensory hair cell death (Forge et al., 2013). In this instance, supporting cells expand to fill the voids left by dead hair cells and restore epithelial tight junction integrity. In $\mathrm{C} \times 30^{-/-}$mice, supporting cells not only display defects in repairing the space left by dead hair cells, they also develop a highly unusual migratory phenotype, despite still expressing Cx26, suggesting that $\mathrm{Cx} 30$ plaques may be important in controlling cell responses to injury (Forge et al., 2013). The inability of terminally differentiated keratinocytes and cochlear supporting cells to proliferate suggests that long-lived $\mathrm{Cx} 30$ gap junctions may help to regulate GJIC or cell-cell adhesion properties to collectively coordinate and control wound healing responses.

Finally, our studies revealed that $\mathrm{Cx} 30$ was arranged into distinct subdomains within plaques co-expressing $\mathrm{Cx} 43$, whereas Cx30 and Cx26 fully intermixed. Similar findings have been shown for Cx26 and Cx43 (Falk, 2000) and more recently with Cx30 and Cx43 (Stout et al., 2015). However, Stout and colleagues went on to suggest that $\mathrm{Cx} 30$ and $\mathrm{Cx} 43$ segregation is attributed to using non-monomeric GFP tags at the C-terminus of $\mathrm{Cx} 30$. When a monomeric variant of GFP was used, Cx30 and Cx43 no longer segregated into distinct domains (Stout et al., 2015), suggesting that the tag was governing the connexin segregation. However, we found that untagged $\mathrm{Cx} 43$ and $\mathrm{Cx} 30$ segregate from each other in NRK cells expressing both connexins, suggesting that, at least in some cells, they may retain innate properties to segregate that are independent of issues related to tagging. These findings are in agreement with previous reports that $\alpha$ - (e.g. $\mathrm{Cx} 43$ ) and $\beta$-connexins (e.g. Cx26 and now Cx30) fail to intermix within gap junction channels (Gemel et al., 2004), whereas $\mathrm{Cx} 26$ and $\mathrm{Cx} 30$ have been shown to form intermixed heteromeric gap junctions (Forge et al., 2003b; Yum et al., 2007). How connexins intermix within channels and gap junctions probably has importance when considering the nature of connexin-linked diseases. For example, mutations in the $\mathrm{Cx} 30$ gene $(G J B 6)$ can cause palmoplantar hyperkeratosis, Clouston Syndrome and/or hearing loss. Whether these clinical presentations are associated with the disruption of the normal Cx30 life cycle or function, or whether they are due to any gainof- or loss-of-function mutant effect on other co-expressed connexins, remains poorly understood. Surprisingly, we have previously shown that some $\mathrm{Cx} 30$ mutants acquire new properties and can affect the localization of $\mathrm{Cx} 43$ (Berger et al., 2014), even though here we show that wild-type $\mathrm{Cx} 30$ remains in distinct subplaque domains from $\mathrm{Cx} 43$. One explanation for connexin segregation could be due to the wealth of $\mathrm{Cx} 43$ binding partners while the interactome for $\mathrm{Cx} 30$ is limited due to the small C-terminal domain (Laird, 2010). As an example, ZO-1 binds to the C-terminal tail of Cx43 (Giepmans et al., 2001b), but does not bind to $\mathrm{Cx} 30$ (Qu et al., 2009), suggesting that ZO-1 could be a candidate for preventing the intermixing of $\mathrm{Cx} 30$ and $\mathrm{Cx} 43$ in keratinocytes.

In conclusion, this is the first study to demonstrate that $\mathrm{Cx} 30$ exhibits an unusually long half-life at the cell surface and that disruption of either the actin or tubulin cytoskeletal networks does not affect $\mathrm{Cx} 30$ gap junction stability. Interestingly, the main tissue-specific cell types that express large amounts of Cx30, namely the keratinocytes and inner ear supporting cells, are either terminally differentiated or quiescent and are often found in avascular tissue regions. These findings suggest that long-lived Cx30 gap junctions between cells that have exited the cell cycle and have reduced metabolism rates are important to: (i) maintain adequate levels of GJIC, (ii) conserve energy by reducing the need to constantly replenish gap junction plaques and (iii) promote cell-cell adhesion, which may ultimately control processes such as migration during wound healing. These unique features may explain why mutations in the $\mathrm{Cx} 30$ gene $(G J B 6)$ are so detrimental to normal physiology. 


\section{MATERIALS AND METHODS}

\section{Generation of cDNA constructs}

To create stable Cx26-, Cx30- and Cx43-expressing HeLa cells: the rat Cx26 pCR3 construct was a gift from Dr W. H. Evans and Dr P. Martin, University of Wales College of Medicine, UK (Martin et al., 1999), and mouse Cx30 pCR3 construct was generated as described previously (Marziano et al., 2003). All other experiments used the following DNA constructs: mouse Cx30 encoded within the pBluescript vector was kindly provided by Dr C. Naus (University of British Colombia, BC). To create a GFP-tagged construct, Cx30 cDNA was subcloned into a pEGFP-N1 (Clontech) expression vector, as described previously (Berger et al., 2014). Sar1 and Sar1 ${ }^{\mathrm{H} 79 \mathrm{G}}$ cDNA were cloned into pDsRed2-N1 (Clontech) vectors as described previously (Thomas et al., 2005).

\section{Cell culture, transfections and generation of stable cell lines}

All media and reagents were obtained from Invitrogen/Life Technologies unless stated otherwise. Rat epidermal keratinocytes (REKs) were kindly provided by Vincent C. Hascall (Cleveland Clinic, OH). HeLa and normal rat kidney (NRK-52E) cells were obtained from the American Type Culture Collection (ATCC). The HeLa cell line stably expressing mouse $\mathrm{Cx} 43$ was kindly provided by Professor N. Severs (Imperial College London, UK) and was maintained under hygromycin B $(250 \mu \mathrm{g} / \mathrm{ml})$ selection.

All cells were grown in high glucose Dulbecco's modified Eagle's medium (DMEM) supplemented with 10\% fetal bovine serum, 1\% penicillin/streptomycin, and $2 \mathrm{mM}$ L-glutamine ('DMEM complete'). For transient transfections cells were grown to $70-80 \%$ confluency and transfected with 1-3 $\mu \mathrm{g}$ DNA using Lipofectamine 2000, according to the manufacturer's guidelines. For co-transfections $1 \mu \mathrm{g}$ DNA of each construct (for a total of $2 \mu \mathrm{g}$ ) was used. Experiments were performed $24 \mathrm{~h}$ later. To obtain stably transfected Cx26 and Cx30 HeLa cell lines, the cells were split $48 \mathrm{~h}$ after transfection into several $10 \mathrm{~cm}$ culture dishes containing DMEM and $500 \mu \mathrm{g} / \mathrm{ml}$ of the selection antibiotic Geneticin (G418). After 7 days, the concentration of G418 was reduced to $250 \mu \mathrm{g} / \mathrm{ml}$ to prevent cytotoxic effects. Individual cell colonies with a diameter of 2-3 $\mathrm{mm}$ were harvested using trypsin-soaked sterile cloning discs ( $3 \mathrm{~mm}$, Sigma-Aldrich) and transferred to a 24-well plate. Clonal cells were plated onto coverslips between harvesting, fixed and checked for connexin expression using immunofluorescent labelling, as described later.

NRK cells were engineered to stably express mouse Cx30 by retroviral infection using the replication-defective AP2 vector (Galipeau et al., 1999) as described previously (Mao et al., 2000; Qin et al., 2002; Thomas et al., 2004). Briefly, the AP- 2 vector containing Cx30 cDNA was transfected into the $293 \mathrm{GPG}$ packaging cell line. Supernatants containing retroviral particles were collected, filter sterilized through a $0.45 \mu \mathrm{m}$ filter (Pall Gelman Laboratories) and added to the NRK cells. After three rounds of infection, the cells were passaged and single cell colonies were selected. Clones with $100 \%$ Cx30 expression were selected for further experimentation.

\section{Drug treatments}

To block ER-to-Golgi transport, connexin-expressing cells were treated with $5 \mu \mathrm{g} / \mathrm{ml}$ brefeldin A (BFA; Sigma-Aldrich) for up to $18 \mathrm{~h}$ in DMEM complete medium at $37^{\circ} \mathrm{C}$. To examine the relative half-life of $\mathrm{Cx} 30$, REKs were treated with $10 \mu \mathrm{g} / \mathrm{ml}$ of the translational inhibitor cycloheximide (CHX; Sigma-Aldrich). To elucidate the role of cytoskeletal elements in the stabilization of connexin plaques, $\mathrm{Cx} 30$ - and $\mathrm{Cx} 43$-expressing REKs were treated with the microtubule-disrupting drug nocodazole $(10 \mu \mathrm{M}$; SigmaAldrich) or with the actin depolymerization drug cytochalasin B $(2.5 \mu \mathrm{g} / \mathrm{ml}$; Sigma-Aldrich) for up to $10 \mathrm{~h}$ in DMEM complete medium at $37^{\circ} \mathrm{C}$.

\section{Live cell time-lapse imaging and fluorescence recovery after photobleaching}

Cells expressing Cx30-GFP were plated into $35 \mathrm{~mm}$ glass-bottomed dishes (MatTek). The dishes were mounted on a Zeiss 510 confocal microscope fitted with a temperature $\left(37^{\circ} \mathrm{C}\right)$ and $\mathrm{CO}_{2}(5 \%)$ control unit. Optical sections at a single $z$-plane or in $z$-stack were acquired every $20-30 \mathrm{~s}$ for up to $2 \mathrm{~h}$ using a $63 \times$ oil immersion lens (numerical aperture 1.4). Cx30-GFP was excited using a $488 \mathrm{~nm}$ argon laser and emitted fluorescence was collected after passage through a 500-550 $\mathrm{nm}$ band pass filter. In some cases, fluorescent images were simultaneously acquired and superimposed over a differential interference contrast (DIC) image. FRAP was performed on specific Cx30-GFP gap junctions as described previously (Thomas et al., 2005; Simek et al., 2009). Briefly, using ZEN 2011 (Zeiss) software a region of interest (ROI) was drawn around the plaque to be bleached. After acquiring 5-10 images at 20-30 s intervals, the 'Edit Bleach' function was programmed to bleach the ROI using 30-60 iterations of the 488 laser at $100 \%$ emission intensity. Recovery of GFP fluorescence was then recorded using the 'Time Series' function by continuously acquiring single $z$-plane or $z$-stack images every $20-30 \mathrm{~s}$ for up to $2 \mathrm{~h}$ of total imaging time, using the $488 \mathrm{~nm}$ laser line at $0.5 \%$ intensity. Three-dimensional time-lapse recordings were reconstructed from the $z$-stack images using the ZEN 2011 3D software tool and exported as still images. The 3D time-lapse movies were created using Imaris 7.0 (Bitplane).

\section{Immunofluorescent labelling}

Cells expressing $\mathrm{Cx} 30$ or $\mathrm{Cx} 43$ were fixed with $10 \%$ neutral buffered formalin, permeabilized and blocked with $0.1 \%$ Triton X-100 (Sigma) and $3 \%$ bovine serum albumin (Santa Cruz Biotechnology) in phosphatebuffered saline (PBS). The following primary antibodies were left on the cells for $2 \mathrm{~h}$ at room temperature or at $4^{\circ} \mathrm{C}$ overnight: rabbit polyclonal anti-Cx30 $(0.63 \mu \mathrm{g} / \mathrm{ml}$, Invitrogen, no. 71-2200), rabbit polyclonal antiCx43 (1.4 $\mu \mathrm{g} / \mathrm{ml}$, Sigma-Aldrich, no. C6219), rabbit polyclonal anti-Cx26 $(1.25 \mu \mathrm{g} / \mathrm{ml}$, Invitrogen, no. 51-2800), mouse monoclonal anti-Cx43 (1:200 dilution, EMD Millipore, no. 05-763), mouse monoclonal anti-GM130 $(0.63 \mu \mathrm{g} / \mathrm{ml}$, BD Biosciences, no. 610822), mouse monoclonal anti-PDI $(3.3 \mu \mathrm{g} / \mathrm{ml}$, Enzo Life Sciences, no. ADI-SPA-891), mouse monoclonal anti- $\beta$-tubulin ( $2 \mu \mathrm{g} / \mathrm{ml}$, Sigma-Aldrich, no. T8328). After washing in PBS, cells were incubated for $1 \mathrm{~h}$ with the following secondary antibodies: goat anti-mouse Alexa Fluor 488 or 555 (1:500 dilution, Invitrogen, no. A11017/ A21425) or goat anti-rabbit Alexa Fluor 488 or 555 (1:500 dilution, Invitrogen, no. A11008/A21429). F-actin filaments were labelled with phalloidin conjugated to Alexa Fluor 568 (1:500 dilution, Invitrogen, no. A12380) or Alexa Fluor 488 (1:500 dilution, Invitrogen, no. A12379). Nuclei were stained with Hoechst $33342(10 \mu \mathrm{g} / \mathrm{ml}$, Invitrogen, no. 62249) or TO-PRO-3 (1:3000, Invitrogen, no. T3605) for $5 \mathrm{~min}$. Cells were washed with PBS, mounted on slides and imaged on a Zeiss 510 Meta confocal microscope using a $63 \times$ oil immersion lens (1.4 numerical aperture).

\section{Whole-cell tracer diffusion assay}

To assess the extent of gap junctional coupling between stably expressing Cx26, Cx30 or Cx43 HeLa cells after BFA treatment, a whole-cell neurobiotin tracer study was performed as described previously (Kelly et al., 2011). Briefly, HeLa cells grown on glass coverslips were pretreated with BFA for $7 \mathrm{~h}$ or $0.01 \%(\mathrm{v} / \mathrm{v})$ ethanol as a control. Coverslips were placed in a recording chamber on an upright microscope (Axioskop; Zeiss) and superfused with artificial extracellular solution (in mM: $145 \mathrm{NaCl}, 4 \mathrm{KCl}$, $2 \mathrm{MgCl}_{2}, 1.3 \mathrm{CaCl}_{2}$ and 5 glucose; $\mathrm{pH}$ adjusted to 7.3 with $\mathrm{NaOH}$ ). Patch pipettes were filled with a potassium chloride intracellular solution (in $\mathrm{mM}$ : $140 \mathrm{KCl}, 10 \mathrm{NaCl}, 2 \mathrm{MgCl}_{2}, 5$ HEPES, 5 EGTA and 5 glucose; $\mathrm{pH}$ adjusted to 7.3 with $\mathrm{KOH}$ ) supplemented with $1 \mathrm{mg} / \mathrm{ml}$ neurobiotin (molecular mass $287 \mathrm{Da}$; charge +1 , Vector Laboratories). Once a giga-seal was formed, suction was applied to create the whole-cell configuration and to allow neurobiotin to permeate the cell. After $10 \mathrm{~min}$ the pipette was gently removed to form a tight seal. Cells were then fixed in $4 \%$ paraformaldehyde for $30 \mathrm{~min}$, permeabilized and blocked in $0.1 \%$ Triton X-100 and $0.1 \mathrm{~mol} / 1$ L-lysine for $30 \mathrm{~min}$, before incubation for $2 \mathrm{~h}$ with Alexa Fluor 555conjugated streptavidin $(1: 1000$; Invitrogen, no. S-32355). Images were acquired on a Zeiss LSM 510 confocal microscope. All image settings were kept constant between coverslips. ImageJ software was used to count cells with neurobiotin present in the cytoplasm and nucleus. Data were collated, presented as means \pm s.e.m. and statistically analysed using Student's $t$-test in GraphPad Prism4 software.

\section{Western blotting}

$\mathrm{Cx} 30$ - and $\mathrm{Cx} 43$-expressing REK protein lysates were collected with a $1 \%$ Triton X-100 lysis buffer, as described previously (Penuela et al., 2007). 
Protein concentrations were measured using a bicinchoninic acid (BCA) protein determination kit (Pierce). In total, 20-30 $\mu \mathrm{g}$ of protein was resolved using $10 \%$ SDS-PAGE and transferred to a nitrocellulose membrane using the iBlot Dry Blotting System (Invitrogen). Membranes were blocked with 3\% bovine serum albumin (BSA)-PBS containing $0.01 \%$ Tween and probed with rabbit polyclonal anti-Cx30 $(0.25 \mu \mathrm{g} / \mathrm{ml}$, Invitrogen, no. 71-2200), rabbit polyclonal anti-Cx43 $(0.55 \mu \mathrm{g} / \mathrm{ml}$, Sigma-Aldrich, no. C6219) and mouse monoclonal GAPDH $(0.1 \mu \mathrm{g} / \mathrm{ml}$, Millipore, no. MAB374). Primary antibodies were detected using the fluorescently conjugated secondary antibodies goat anti-rabbit IRdye $800 \quad(1: 10,000$ dilution, LI-COR Biosciences) and Alexa Fluor 680 goat anti-mouse (1:10,000 dilution, Invitrogen, no. A21057). Membranes were scanned and quantified using the Odyssey Infrared Imaging System (LI-COR Biosciences). For CHX experiments, band intensities, normalized to the $0 \mathrm{~h}$ time point, were collated and a one-way ANOVA was performed on the averages of three biological replicates. Densitometry units are displayed \pm s.e.m.

\section{Triton solubility assay}

$\mathrm{Cx} 30$ - and Cx43-expressing REKs grown in $60 \mathrm{~mm}$ dishes were pretreated with BFA for $7 \mathrm{~h}$, washed with cold PBS and Triton solubility assessed as described previously (Langlois et al., 2008), with modifications. Briefly, cells were gently collected with a rubber policeman into $1 \mathrm{ml}$ of cold PBS and spun down to a pellet. Cells were gently resuspended in $300 \mu \mathrm{l}$ Triton lysis buffer containing $1 \%$ Triton $\mathrm{X}-100$ plus $5 \mathrm{mM}$ Tris- $\mathrm{HCl}(\mathrm{pH} 8.0)$, $2 \mathrm{mM}$ EDTA, $2 \mathrm{mM}$ EGTA, $1 \mathrm{mM} \mathrm{NaF}, 1 \mathrm{mM} \mathrm{Na} \mathrm{VO}_{4}$ and protease inhibitor (Roche). Cells were left for $30 \mathrm{~min}$ on ice before pelleting and collecting the Triton-soluble supernatant. The remaining Triton-insoluble material was then dissolved in lysis buffer containing 1\% SDS with sonication. Equal volumes of Triton X-100 soluble and insoluble fractions were separated by SDS-PAGE and subjected to western blotting. GAPDH was used to verify the quality of the isolated fractions. Densitometry data are presented as means \pm s.e.m. and were statistically analysed using Student's $t$-test in GraphPad Prism4 software.

\section{Acknowledgements}

We thank Dr Regina Nickel for help in establishing the stable Cx26 and Cx30 HeLa cell lines, Professor Andrew Forge for advice, Vanessa DeMelo for her assistance with the cycloheximide experiments and Lianne Dale for help with image processing. We also thank Dr Christian C. Naus (University of British Columbia, Vancouver, Canada) for the Cx30-pBluescript vector, Dr W. Howard Evans and Dr Patricia Martin (Glasgow Caledonian University, Glasgow, UK) for the Cx26-pCR3 vector, as well as Dr Vincent C. Hascall (Cleveland Clinic, Cleveland, USA) and Dr Nicholas Severs (Imperial College London, London, UK) for providing the REKs and the HeLa-Cx43 cell line, respectively.

\section{Competing interests}

The authors declare no competing or financial interests.

\section{Author contributions}

J.J.K. performed all experiments with assistance from D.J.J. for whole-cell patch clamp experiments. J.J.K., Q.S., D.J.J. and D.W.L. designed the experiments. J.J.K. wrote the manuscript. D.W.L. edited the manuscript.

\section{Funding}

This work was primarily supported by a Canadian Institutes of Health Research grant to D.W.L. [grant number 123228]; and also in part by a Royal Society University Research Fellowship to D.J.J. and Deafness Research UK PhD studentship to J.J.K.

\section{Supplementary information}

Supplementary information available online at

http://jcs.biologists.org/lookup/suppl/doi:10.1242/jcs.174698/-/DC1

\section{References}

Adams, M. P., Mallet, D. G. and Pettet, G. J. (2012). Active regulation of the epidermal calcium profile. J. Theor. Biol. 301, 112-121.

Ahmad, S. and Evans, W. H. (2002). Post-translational integration and oligomerization of connexin 26 in plasma membranes and evidence of formation of membrane pores: implications for the assembly of gap junctions. Biochem. J. 365, 693-699.
Ahmad, S., Diez, J. A., George, C. H. and Evans, W. H. (1999). Synthesis and assembly of connexins in vitro into homomeric and heteromeric functional gap junction hemichannels. Biochem. J. 339, 247-253.

Alexander, D. B. and Goldberg, G. S. (2003). Transfer of biologically important molecules between cells through gap junction channels. Curr. Med. Chem. 10 2045-2058.

Bhalla-Gehi, R., Penuela, S., Churko, J., Shao, Q. and Laird, D. W. (2010). Pannexin1 and Pannexin3 delivery, cell surface dynamics and cytoskeletal interactions. J. Biol. Chem. 285, 9147-9160.

Beardslee, M. A., Laing, J. G., Beyer, E. C. and Saffitz, J. E. (1998). Rapid turnover of connexin43 in the adult rat heart. Circ. Res. 83, 629-635.

Berger, A. C., Kelly, J. J., Lajoie, P., Shao, Q. and Laird, D. W. (2014). Mutations in Cx30 that are linked to skin disease and non-syndromic hearing loss exhibit several distinct cellular pathologies. J. Cell Sci. 127, 1751-1764.

Berthoud, V. M., Bassnett, S. and Beyer, E. C. (1999). Cultured chicken embryo lens cells resemble differentiating fiber cells in vivo and contain two kinetic pools of connexin56. Exp. Eye Res. 68, 475-484.

Bosen, F., Schütz, M., Beinhauer, A., Strenzke, N., Franz, T. and Willecke, K. (2014). The Clouston syndrome mutation connexin30 A88V leads to hyperproliferation of sebaceous glands and hearing impairments in mice. FEBS Lett. 588, 1795-1801.

Chang, Q., Tang, W., Ahmad, S., Zhou, B. and Lin, X. (2008). Gap junction mediated intercellular metabolite transfer in the cochlea is compromised in connexin30 null mice. PLOS ONE 3, e4088.

Chen, P., Zindy, F., Abdala, C., Liu, F., Li, X., Roussel, M. F. and Segil, N. (2003) Progressive hearing loss in mice lacking the cyclin-dependent kinase inhibitor Ink4d. Nat. Cell Biol. 5, 422-426.

Churko, J. M. and Laird, D. W. (2013). Gap junction remodeling in skin repair following wounding and disease. Physiology 28, 190-198.

Coutinho, P., Qiu, C., Frank, S., Tamber, K. and Becker, D. (2003). Dynamic changes in connexin expression correlate with key events in the wound healing process. Cell Biol. Int. 27, 525-541.

Dahl, E., Manthey, D., Chen, Y., Schwarz, H.-J., Chang, Y. S., Lalley, P. A. Nicholson, B. J. and Willecke, K. (1996). Molecular cloning and functional expression of mouse connexin-30, a gap junction gene highly expressed in adult brain and skin. J. Biol. Chem. 271, 17903-17910.

Darrow, B. J., Laing, J. G., Lampe, P. D., Saffitz, J. E. and Beyer, E. C. (1995). Expression of multiple connexins in cultured neonatal rat ventricular myocytes. Circ. Res. 76, 381-387.

Das, S., Smith, T. D., Sarma, J. D., Ritzenthaler, J. D., Maza, J., Kaplan, B. E., Cunningham, L. A., Suaud, L., Hubbard, M. J., Rubenstein, R. C. et al. (2009). ERp29 restricts Connexin43 oligomerization in the endoplasmic reticulum. Mol. Biol. Cell 20, 2593-2604.

Di, W.-L., Rugg, E. L., Leigh, I. M. and Kelsell, D. P. (2001). Multiple epiderma connexins are expressed in different keratinocyte subpopulations including connexin 31. J. Invest. Dermatol. 117, 958-964.

Elias, L. A. B., Wang, D. D. and Kriegstein, A. R. (2007). Gap junction adhesion is necessary for radial migration in the neocortex. Nature 448, 901-907.

Essenfelder, G. M., Bruzzone, R., Lamartine, J., Charollais, A., BlanchetBardon, C., Barbe, M. T., Meda, P. and Waksman, G. (2004). Connexin30 mutations responsible for hidrotic ectodermal dysplasia cause abnormal hemichannel activity. Hum. Mol. Genet. 13, 1703-1714.

Evans, W. H., De Vuyst, E. and Leybaert, L. (2006). The gap junction cellular internet: connexin hemichannels enter the signalling limelight. Biochem. J. 397 1-14.

Falk, M. M. (2000). Connexin-specific distribution within gap junctions revealed in living cells. J. Cell Sci. 113, 4109-4120.

Falk, M. M., Baker, S. M., Gumpert, A. M., Segretain, D. and Buckheit, R. W.III (2009). Gap junction turnover is achieved by the internalization of small endocytic double-membrane vesicles. Mol. Biol. Cell 20, 3342-3352.

Falk, M. M., Fong, J. T., Kells, R. M., O'Laughlin, M. C., Kowal, T. J. and Thévenin, A. F. (2012). Degradation of endocytosed gap junctions by autophagosomal and endo-/lysosomal pathways: a perspective. J. Membr. Biol. 245, 465-476.

Fallon, R. F. and Goodenough, D. A. (1981). Five-hour half-life of mouse liver gapjunction protein. J. Cell Biol. 90, 521-526.

Forge, A., Becker, D., Casalotti, S., Edwards, J., Marziano, N. and Nevill, G. (2003a). Gap junctions in the inner ear: comparison of distribution patterns in different vertebrates and assessement of connexin composition in mammals. J. Comp. Neurol. 467, 207-231.

Forge, A., Marziano, N. K., Casalotti, S. O., Becker, D. L. and Jagger, D. (2003b). The inner ear contains heteromeric channels composed of cx26 and cx30 and deafness-related mutations in cx26 have a dominant negative effect on cx30. Cell Commun. Adhes. 10, 341-346.

Forge, A., Jagger, D. J., Kelly, J. J. and Taylor, R. R. (2013). Connexin30mediated intercellular communication plays an essential role in epithelial repair in the cochlea. J. Cell Sci. 126, 1703-1712.

Gaietta, G., Deerinck, T. J., Adams, S. R., Bouwer, J., Tour, O., Laird, D. W., Sosinsky, G. E., Tsien, R. Y. and Ellisman, M. H. (2002). Multicolor and electron microscopic imaging of connexin trafficking. Science 296, 503-507. 
Galipeau, J., Li, H., Paquin, A., Sicilia, F., Karpati, G. and Nalbantoglu, J. (1999). Vesicular stomatitis virus G pseudotyped retrovector mediates effective in vivo suicide gene delivery in experimental brain cancer. Cancer Res. 59, 2384-2394

Gemel, J., Valiunas, V., Brink, P. R. and Beyer, E. C. (2004). Connexin43 and connexin26 form gap junctions, but not heteromeric channels in co-expressing cells. J. Cell Sci. 117, 2469-2480

George, C. H., Kendall, J. M. and Evans, W. H. (1999). Intracellular trafficking pathways in the assembly of connexins into gap junctions. J. Biol. Chem. 274 8678-8685.

Giepmans, B. N. G., Verlaan, I., Hengeveld, T., Janssen, H., Calafat, J., Falk, M. M. and Moolenaar, W. H. (2001a). Gap junction protein connexin-43 interacts directly with microtubules. Curr. Biol. 11, 1364-1368.

Giepmans, B. N., Verlaan, I. and Moolenaar, W. H. (2001b). Connexin-43 interactions with ZO-1 and alpha- and beta-tubulin. Cell. Commun. Adhes. 8 , 219-223.

Grifa, A., Wagner, C. A., D’Ambrosio, L., Melchionda, S., Bernardi, F., LopezBigas, N., Rabionet, R., Arbones, M., Monica, M. D., Estivill, X. et al. (1999). Mutations in GJB6 cause non-syndromic autosomal dominant deafness at DFNA3 locus. Nat. Genet. 23, 16-18

Jagger, D. J. and Forge, A. (2006). Compartmentalized and signal-selective gap junctional coupling in the hearing cochlea. J. Neurosci. 26, 1260-1268.

Jagger, D. J. and Forge, A. (2014). Connexins and gap junctions in the inner ear it's not just about K recycling. Cell Tissue Res. 360, 633-644.

Jiang, J. X., Paul, D. L. and Goodenough, D. A. (1993). Posttranslationa phosphorylation of lens fiber connexin46: a slow occurrence. Invest Ophthalmol. Vis. Sci. 34, 3558-3565.

Jordan, K., Solan, J. L., Dominguez, M., Sia, M., Hand, A., Lampe, P. D. and Laird, D. W. (1999). Trafficking, assembly, and function of a connexin43-green fluorescent protein chimera in live mammalian cells. Mol. Biol. Cell 10 2033-2050.

Jordan, K., Chodock, R., Hand, A. R. and Laird, D. W. (2001). The origin of annular junctions: a mechanism of gap junction internalization. J. Cell Sci. 114 763-773

Kelly, J. J., Forge, A. and Jagger, D. J. (2011). Development of gap junctiona intercellular communication within the lateral wall of the rat cochlea. Neuroscience 180, 360-369.

Kretz, M., Euwens, C., Hombach, S., Eckardt, D., Teubner, B., Traub, O., Willecke, K. and Ott, T. (2003). Altered connexin expression and wound healing in the epidermis of connexin-deficient mice. J. Cell Sci. 116, 3443-3452.

Kunzelmann, P., Schröder, W., Traub, O., Steinhäuser, C., Dermietzel, R. and Willecke, K. (1999). Late onset and increasing expression of the gap junction protein connexin30 in adult murine brain and long-term cultured astrocytes. Glia 25, 111-119.

Laing, J. G., Tadros, P. N., Westphale, E. M. and Beyer, E. C. (1997). Degradation of connexin43 gap junctions involves both the proteasome and the lysosome. Exp. Cell Res. 236, 482-492.

Laird, D. W. (2006). Life cycle of connexins in health and disease. Biochem. J. 394 527-543.

Laird, D. W. (2010). The gap junction proteome and its relationship to disease. Trends Cell. Biol. 20, 92-101.

Laird, D. W., Puranam, K. L. and Revel, J. P. (1991). Turnover and phosphorylation dynamics of connexin43 gap junction protein in cultured cardiac myocytes. Biochem. J. 273, 67-72

Laird, D. W., Castillo, M. and Kasprzak, L. (1995). Gap junction turnover, intracellular trafficking, and phosphorylation of connexin43 in brefeldin A-treated rat mammary tumor cells. J. Cell Biol. 131, 1193-1203.

Lampe, P. D. and Lau, A. F. (2000). Regulation of gap junctions by phosphorylation of connexins. Arch. Biochem. Biophys. 384, 205-215.

Langlois, S., Cowan, K. N., Shao, Q., Cowan, B. J. and Laird, D. W. (2008) Caveolin-1 and -2 interact with connexin43 and regulate gap junctional intercellular communication in keratinocytes. Mol. Biol. Cell 19, 912-928.

Lauf, U., Giepmans, B. N. G., Lopez, P., Braconnot, S., Chen, S.-C. and Falk M. M. (2002). Dynamic trafficking and delivery of connexons to the plasma membrane and accretion to gap junctions in living cells. Proc. Natl. Acad. Sci. USA 99, 10446-10451.

Leithe, E., Sirnes, S., Fykerud, T., Kjenseth, A. and Rivedal, E. (2012) Endocytosis and post-endocytic sorting of connexins. Biochim. Biophys. Acta 1818, 1870-1879.

Lowenheim, H., Furness, D. N., Kil, J., Zinn, C., Gultig, K., Fero, M. L., Frost, D., Gummer, A. W., Roberts, J. M., Rubel, E. W. et al. (1999). Gene disruption of p27Kip1 allows cell proliferation in the postnatal and adult organ of Corti. Proc. Natl. Acad. Sci. USA 96, 4084-4088.

Mansour, H., McColm, J. R., Cole, L., Weible, M., II, Korlimbinis, A. and ChanLing, T. (2013). Connexin 30 expression and frequency of connexin heterogeneity in astrocyte gap junction plaques increase with age in the rat retina. PLOS ONE 8 e57038.

Mao, A. J., Bechberger, J., Lidington, D., Galipeau, J., Laird, D. W. and Naus, C. C. G. (2000). Neuronal differentiation and growth control of neuro-2a cells after retroviral gene delivery of connexin43. J. Biol. Chem. 275 34407-34414

Martin, P. E. M., Coleman, S. L., Casalotti, S. O., Forge, A. and Howard Evans, W. (1999). Properties of connexin26 gap junctional proteins derived from mutations associated with non-syndromal heriditary deafness. Hum. Mol. Genet. 8, 2369-2376.

Martin, P. E., Blundell, G., Ahmad, S., Errington, R. J. and Evans, W. H. (2001). Multiple pathways in the trafficking and assembly of connexin 26, 32 and 43 into gap junction intercellular communication channels. J. Cell Sci. 114, 3845-3855.

Martin, P. E., Easton, J. A., Hodgins, M. B. and Wright, C. S. (2014). Connexins: sensors of epidermal integrity that are therapeutic targets. FEBS Lett. $\mathbf{5 8 8}$ 1304-1314.

Marziano, N. K., Casalotti, S. O., Portelli, A. E., Becker, D. L. and Forge, A. (2003). Mutations in the gene for connexin 26 (GJB2) that cause hearing loss have a dominant negative effect on connexin 30. Hum. Mol. Genet. 12, 805-812.

Mathias, R. T., White, T. W. and Gong, X. (2010). Lens gap junctions in growth, differentiation and homeostasis. Physiol. Rev. 90, 179-206.

Menon, G. K., Grayson, S. and Elias, P. M. (1985). Ionic calcium reservoirs in mammalian epidermis: ultrastructural localization by ion-capture cytochemistry. J. Invest. Dermatol. 84, 508-512.

Musil, L. S. and Goodenough, D. A. (1993). Multisubunit assembly of an integral plasma membrane channel protein, gap junction connexin43, occurs after exit from the ER. Cell 74, 1065-1077.

Penuela, S., Bhalla, R., Gong, X.-Q., Cowan, K. N., Celetti, S. J., Cowan, B. J., Bai, D., Shao, Q. and Laird, D. W. (2007). Pannexin 1 and pannexin 3 are glycoproteins that exhibit many distinct characteristics from the connexin family of gap junction proteins. J. Cell Sci. 120, 3772-3783.

Piehl, M., Lehmann, C., Gumpert, A., Denizot, J.-P., Segretain, D. and Falk, M. M. (2007). Internalization of large double-membrane intercellular vesicles by a clathrin-dependent endocytic process. Mol. Biol. Cell 18, 337-347.

Qin, H., Shao, Q., Curtis, H., Galipeau, J., Belliveau, D. J., Wang, T., AlaouiJamali, M. A. and Laird, D. W. (2002). Retroviral delivery of connexin genes to human breast tumor cells inhibits in vivo tumor growth by a mechanism that is independent of significant gap junctional intercellular communication. J. Biol. Chem. 277, 29132-29138.

Qu, C., Gardner, P. and Schrijver, I. (2009). The role of the cytoskeleton in the formation of gap junctions by Connexin 30. Exp. Cell Res. 315, 1683-1692.

Richard, G. (2003). Connexin gene pathology. Clin. Exp. Dermatol. 28, 397-409.

Schutz, M., Scimemi, P., Majumder, P., De Siati, R. D., Crispino, G., Rodriguez, L., Bortolozzi, M., Santarelli, R., Seydel, A., Sonntag, S. et al. (2010). The human deafness-associated connexin 30 T5M mutation causes mild hearing loss and reduces biochemical coupling among cochlear non-sensory cells in knock-in mice. Hum. Mol. Genet. 19, 4759-4773.

Shaw, R. M., Fay, A. J., Puthenveedu, M. A., von Zastrow, M., Jan, Y.-N. and Jan, L. Y. (2007). Microtubule plus-end-tracking proteins target gap junctions directly from the cell interior to adherens junctions. Cell 128, 547-560.

Shurman, D. L., Glazewski, L., Gumpert, A., Zieske, J. D. and Richard, G. (2005) In vivo and in vitro expression of connexins in the human corneal epithelium. Invest. Ophthalmol. Vis. Sci. 46, 1957-1965.

Simek, J., Churko, J., Shao, Q. and Laird, D. W. (2009). Cx43 has distinct mobility within plasma-membrane domains, indicative of progressive formation of gap junction plaques. J. Cell Sci. 122, 554-562.

Slavi, N., Rubinos, C., Li, L., Sellitto, C., White, T. W., Mathias, R. and Srinivas M. (2014). Connexin 46 (cx46) gap junctions provide a pathway for the delivery of glutathione to the lens nucleus. J. Biol. Chem. 289, 32694-32702.

Solan, J. L. and Lampe, P. D. (2014). Specific Cx43 phosphorylation events regulate gap junction turnover in vivo. FEBS Lett. 588, 1423-1429.

Stout, R. F., Jr, Snapp, E. L. and Spray, D. C. (2015). Connexin type and fluorescent protein-fusion tag determine structural stability of gap junction plaques. J. Biol. Chem. 290, 23497-23514

Sun, J., Ahmad, S., Chen, S., Tang, W., Zhang, Y., Chen, P. and Lin, X. (2005) Cochlear gap junctions coassembled from Cx26 and 30 show faster intercellula $\mathrm{Ca}^{2+}$ signaling than homomeric counterparts. Am. J. Physiol. Cell Physiol. 288, C613-C623.

Talhouk, R. S., Elble, R. C., Bassam, R., Daher, M., Sfeir, A., Mosleh, L. A El-Khoury, H., Hamoui, S., Pauli, B. U. and El-Sabban, M. E. (2005) Developmental expression patterns and regulation of connexins in the mouse mammary gland: expression of connexin30 in lactogenesis. Cell Tissue Res. $\mathbf{3 1 9}$ 49-59.

Thomas, T., Jordan, K. and Laird, D. W. (2001). Role of cytoskeletal elements in the recruitment of Cx43-GFP and Cx26-YFP into gap junctions. Cell Commun. Adhes. 8, 231-236.

Thomas, T., Telford, D. and Laird, D. W. (2004). Functional domain mapping and selective trans-dominant effects exhibited by Cx26 disease-causing mutations. J. Biol. Chem. 279, 19157-19168.

Thomas, T., Jordan, K., Simek, J., Shao, Q., Jedeszko, C., Walton, P. and Laird, D. W. (2005). Mechanisms of Cx43 and Cx26 transport to the plasma membrane and gap junction regeneration. J. Cell Sci. 118, 4451-4462. 
Traub, O., Look, J., Dermietzel, R., Brümmer, F., Hulser, D. and Willecke, K. (1989). Comparative characterization of the $21-\mathrm{kD}$ and $26-\mathrm{kD}$ gap junction proteins in murine liver and cultured hepatocytes. J. Cell Biol. 108, 1039-1051.

Vanslyke, J. K., Naus, C. C. and Musil, L. S. (2009). Conformational maturation and post-ER multisubunit assembly of gap junction proteins. Mol. Biol. Cell 20, 2451-2463

Wang, W.-H., Liu, Y.-F., Su, C.-C., Su, M.-C., Li, S.-Y. and Yang, J.-J. (2011). A novel missense mutation in the connexin30 causes nonsyndromic hearing loss. PLOS ONE 6, e21473.
Xu, J. and Nicholson, B. J. (2013). The role of connexins in ear and skin physiology - functional insights from disease-associated mutations. Biochim. Biophys. Acta 1828, 167-178.

Yum, S. W., Zhang, J., Valiunas, V., Kanaporis, G., Brink, P. R., White, T. W. and Scherer, S. S. (2007). Human connexin26 and connexin30 form functional heteromeric and heterotypic channels. Am. J. Physiol. Cell Physiol. 293, C1032-C1048.

Zhang, J. T., Chen, M., Foote, C. I. and Nicholson, B. J. (1996). Membrane integration of in vitro-translated gap junctional proteins: co- and post-translational mechanisms. Mol. Biol. Cell 7, 471-482.

\section{Special Issue on 3D Cell Biology} Call for papers 